NBER WORKING PAPER SERIES

\title{
EMERGING MARKETS SOVEREIGN CDS SPREADS DURING COVID-19: ECONOMICS VERSUS EPIDEMIOLOGY NEWS
}

\author{
Timo Daehler \\ Joshua Aizenman \\ Yothin Jinjarak \\ Working Paper 27903 \\ http://www.nber.org/papers/w27903 \\ NATIONAL BUREAU OF ECONOMIC RESEARCH \\ 1050 Massachusetts Avenue \\ Cambridge, MA 02138 \\ October 2020, Revised March 2021
}

Insightful comments by anonymous referees and the editor are gratefully acknowledged. We gratefully acknowledge the financial support by the Dockson Chair and the Center of International Studies at USC. The views expressed herein are those of the authors and do not necessarily reflect the views of the National Bureau of Economic Research.

NBER working papers are circulated for discussion and comment purposes. They have not been peer-reviewed or been subject to the review by the NBER Board of Directors that accompanies official NBER publications.

(C) 2020 by Timo Daehler, Joshua Aizenman, and Yothin Jinjarak. All rights reserved. Short sections of text, not to exceed two paragraphs, may be quoted without explicit permission provided that full credit, including $(\odot$ notice, is given to the source. 
Emerging Markets Sovereign CDS Spreads During COVID-19: Economics versus Epidemiology News

Timo Daehler, Joshua Aizenman, and Yothin Jinjarak

NBER Working Paper No. 27903

October 2020, Revised March 2021

JEL No. F34,F36,F41,H12,H51

\begin{abstract}
$\underline{\text { ABSTRACT }}$
Can bad news about COVID-19 induce negative expectations on sovereign credit risks? We investigate the factors driving credit default swap (CDS) spreads of emerging market sovereigns around the outbreak of COVID-19. Using 2014-2019 data, we estimate a two-factor model of global and regional risks and then extrapolate the model-implied spreads for the period July 2019-June 2020. Intriguingly, the model initially predicts the realized spreads well but loses predictive accuracy during the COVID-19 pandemic. Fiscal space and oil-revenue dependence primarily drive the differences between the realized and predicted sovereign spreads. Our augmented-factor model indicates that the cumulative COVID-19 mortality rate growth is positively associated with the CDS spreads. The evidence suggests that the epidemiological deterioration can lower confidence in the sovereign credit markets due to the prospects of prolonged lockdowns and a slower GDP growth recovery. Our results also hold for a single regression of daily spread changes during 2014-2020.

Timo Daehler

University of Southern California

3518 Trousdale Pkwy.

Los Angeles, CA 90089

daehler@usc.edu

Joshua Aizenman

Economics and SIR

University of Southern California

University Park

Los Angeles, CA 90089-0043 and

NBER

aizenman@usc.edu

Yothin Jinjarak

School of Economics and Finance

Victoria University of Wellington

PO Box 600

23 Lambton Quay, Wellington

New Zealand

yothin.jinjarak@vuw.ac.nz
\end{abstract}

The code and data are available at https://github.com/timodaehler/COVID19-DOMINANCE/ 


\section{Introduction}

Many emerging market economies (EM) depend on commodity revenues, or on manufacturing exports, whilst they have relatively limited policy space to buffer fluctuations in these markets. Frequently their populations are comparatively exposed to economic fluctuations as social safety nets and public health systems are limited in size. Additionally, emerging market governments' access to international capital markets is fragile, limiting fiscal space and the capacity to react to external shocks. Against this backdrop, many observers were wondering how emerging markets would deal with the global outbreak of COVID-19, an unprecedented shock affecting both sides of the fiscal equation simultaneously: On the revenue side, the global slump in demand caused a fall in oil prices which would diminish oil exporter revenues both directly and indirectly. Equally, a fall of domestic economic activity lowered household incomes and consumer confidence, further reducing tax revenues. On the expenditure side, debt became more costly as a global spike in investors' risk aversion induced capital outflows from emerging markets, an increase in their sovereign credit default swap (CDS) spreads and a depreciation of their currencies (see Figure 1 and Figure 2). The increase in risk aversion, in turn, can be attributed both to economic challenges in investors' home countries and in emerging markets alike. More importantly still, the pandemic forced governments to engage in unparalleled deficit spending to support strained public health systems and households severed from their income sources due to lockdowns (see Figure 3).

The economic challenges caused by the pandemic and the simultaneous oil price collapse are not the first shock that emerging markets face. Indeed, there have been six previous oil price collapses since 1970. Additionally, in recent decades, the increased flow of cross-border investment and trade in a more and more deeply intertwined global economy has been subject to repeated interruption. For example, in 2015, there was a relatively contained crisis in China when the Chinese stock market tumbled, the Yuan slid, and a lot of foreign investment quickly left the country. A year before that, dropping prices of oil and other commodities sent a shock wave through several emerging markets. Furthermore, a general slowdown in emerging market growth began in 2013 with the Federal Reserve's (Fed) taper tantrum. Taken together, these examples indicate that not all crises in emerging markets are the same. Some are more countryspecific while others seem to be driven by some common global factor, affecting emerging markets at large. Thus, with COVID-19 as a global pandemic and an external demand shock, two research questions reveal themselves: Are sovereign CDS spreads determined by a time-varying combination of global and country-specific factors and if the later factors play a role, which ones? Particularly COVID-19 raises a corollary question about country-specific determinants of sovereign CDS spreads: is the epidemiological situation in a country significant for CDS spread determination once the economic repercussions of lockdowns and foreign demand slump as well as stimulus responses are taken into account?

To address the first question, we adopt a two-stage econometric approach, using a panel of thirty investible emerging markets. In the first stage, we estimate a global/regional factor model for changes in sovereign CDS spreads before the outbreak 
of COVID-19. Specifically, we estimate and train the model over the period January 2014 through June 2019. In the second stage, we use the estimated coefficients to extrapolate model-implied changes in CDS spreads for the period July 2019 through June 2020.

This approach is appealing for several reasons: On the one hand, it allows us to compare the model's out-of-sample properties during normal and pandemic times. On the other hand, this approach facilitates the statistical derivation of the "COVID-19 residual," which is the difference between actual CDS changes and model implied changes for the pandemic period. Additionally, the residuals can then be used to answer the question which exact country-specific factors were the biggest drivers of CDS adjustment during COVID-19. Specifically, we explain the residuals through a variety of country-specific factors from three different realms: epidemiological, economic, and policy factors.

To address the second question, we leverage the panel and introduce all control variables (global/regional and country-specific epidemiological, economic and policy factors) simultaneously to test the significance of the epidemiological variables.

Our paper makes two distinct contributions. First, we engage in the discussion of the relative importance and time-varying nature of global/regional and country-specific factors in the determination of emerging markets sovereign risk pricing, particularly during a global pandemic. Second, our analysis contributes to an understanding of the economic effects of lockdowns on government finances by identifying if and which country-specific factors drive spreads during a global pandemic. Disentangling the effects of economic contagion and of domestic economic conditions and policy responses on sovereign CDS spreads promises to hold valuable implications for policy makers weighing the economic trade-offs of different containment strategies.

Our main findings can be summarized as follows:

First, the global/regional factor model traces the realized sovereign CDS spreads well for the out-of-sample period before the pandemic. This observation suggests that emerging market CDS spreads are driven largely by global/regional factors in risk-on environments.

Second, the relationship between actual CDS spread changes and changes predicted by the global/regional factor model breaks down during the pandemic. This suggests that CDS spread determinants are of time-varying nature and that investors weigh country-specific factors more heavily in their decision-making process in risk-off environments.

Third, actual CDS spread changes experience the biggest deviations from modelimplied values in March 2020, suggesting that uncertainties around the ramifications of COVID-19 vary across time and were highest at the peak of the first wave.

Fourth, residuals at peak COVID-19 were primarily driven by traditional country-specific factors of sovereign solvency such as fiscal space and oil income dependence rather than epidemiological factors. This suggests, maybe surprisingly, that the severity of the 
pandemic in terms of mortalities in a specific country didn't influence investors' behavior very much, at least during peak COVID-19.

Fifth, over the entire pandemic period the growth in the cumulative mortality rate is significantly positively related to CDS spread changes after taking the economic ramifications of lockdowns and the oil price decline into account. This suggests that higher COVID-19 mortality rate increases the odds of more prolonged lockdowns and a slower GDP growth recovery, increasing spreads.

The rest of the paper proceeds as follows: Section 2 reviews the literature. Section 3 sets the stage by presenting stylized facts about emerging markets during COVID-19. Section 4 contains the main analysis. Its subsections provide simple economic intuition behind every mechanism that we test and then discuss the results. Section 5 concludes.

\section{Related literature}

There is an ongoing debate about the degree to which country-specific and global/regional factors are drivers of sovereign risk pricing and indeed local financial market conditions more broadly. As an in-depth examination of the existing literature is beyond the scope of this paper, we refer readers to Augustin (2014) for a detailed review of existing studies and only sketch the main research avenues. Generally speaking, there are two camps on opposite sides of the spectrum. One camp proposes a bottom-up logic, arguing that sovereign risk pricing is primarily a function of a country's fundamentals such as a fiscal space, sovereign debt levels, and local economic conditions. In contrast, the other camp argues that country fundamentals are largely negligible and instead stresses the significance of global/regional factors in explaining sovereign risk pricing. Below, we first present a selection of studies from either camp. Then, we present synthesizing studies which provide evidence that suggests that determinants of sovereign risk pricing are time-varying. That is, regional/global and country-specific factors both drive spreads but to degrees which change over time. Based on these findings, we develop simple economic intuitions to explain the mechanisms that we test in the main analysis of this paper.

\subsection{Literature on country-specific drivers of sovereign risk pricing}

Covering the taper-tantrum episode of 2013 and seven other episodes of severe financial turmoil since the mid-1990s, Ahmed et al. (2017) assess the importance of country fundamentals in the transmission of international shocks to financial markets in emerging markets. They find that: 1) Emerging markets with relatively better economic fundamentals suffered less deterioration in financial market conditions during the 2013 episode. 2) Differentiation among emerging markets set in relatively early and persisted through this episode. 3) During the taper tantrum, while controlling for economic fundamentals, financial market conditions also deteriorated more in those emerging markets that had previously experienced larger private capital inflows and greater exchange rate appreciation. 4) During emerging market crises of the 1990s and early 2000s, they find little evidence of investor differentiation across emerging markets being explained by differences in their relative vulnerabilities. 5) Differentiation does not appear to be unique to the 2013 episode; it also occurred during the global financial 
crisis of 2008 and, subsequently, during financial stress episodes related to the European sovereign debt crisis in 2011 and China's financial market turmoil in 2015.

Taking a more focused approach, Kocsis \& Monostori (2016) investigate specifically the determinants of sovereign CDS spreads of Poland, Russia and Turkey. They use a dynamic hierarchical factor model to aggregate information in indicators of economic fundamentals. CDS spreads are then regressed on forecasts of factors. They find that domestic fundamentals explain more of CDS spread variance than global factors which is largely due to their ability to explain differences in sovereign risk across countries.

\subsection{Literature on global drivers of sovereign risk pricing}

The importance of global factors in explaining sovereign risk pricing is usually motivated by the observation that CDS spreads of different countries tend to move in lockstep over longer periods of time. While there are a number of papers pointing out this observation, the most prominent exponent of this theory is Hélène Rey with the notion of a "global financial cycle." Rey (2015) argues that "Risky asset prices around the globe, from stocks to corporate bonds, have a strong common component. So do capital flows ... Global financial cycles are associated with surges and retrenchments in capital flows, booms and busts in asset prices and crises. The picture emerging is that of a world with powerful global financial cycles characterized by large common movements in asset prices, gross flows, and leverage ... The global financial cycle can be related to monetary conditions in the center country and to changes in risk aversion and uncertainty ... capital flows, especially credit flows, are largely driven by a global factor...".

Fender et al. (2012) study the determinants of daily CDS spreads of emerging market sovereigns over the period April 2002 to December 2011. Using GARCH models, they find spreads are more related to global and regional risk premia than to country-specific risk factors. This result is particularly evident during the second subsample (August 2007-December 2011), where neither macroeconomic variables nor country ratings significantly explain CDS spread changes. Second, measures of US bond, equity, and CDX High Yield returns, as well as emerging market credit returns, are the most important drivers of CDS spread changes. Finally, their analysis finds that CDS spreads are more strongly influenced by international spillover effects during periods of market stress than during normal times, suggesting that CDS spread drivers may be timevarying.

\subsection{Literature on time-varying drivers of sovereign risk pricing}

Attempting to synthesize the empirical evidence in favor of both local and global/regional factors, Remolona et al. (2008) decompose sovereign CDS spreads into expected losses from default and the market risk premia required by investors as compensation for default risk over the period 2002 to mid 2006. They find that countryspecific fundamentals primarily drive sovereign risk whilst global investors' risk aversion drives time variation in risk premia. Consistent with this, they also find that within emerging market regions the sovereign risk premia is more highly correlated than 
sovereign risk itself. This finding suggests that there is a third category that drives sovereign risk pricing: regional factors.

By examining the heterogeneity in the sensitivity of CDS spreads to changes in the global risk factor, Cepni et al. (2017) look at the global-vs-local debate through a different lens. Their find that countries with lower government debt and higher reserves tend to be less subject to the variations in global risk appetite. That is, they do not argue that only global/regional or only local factors matter but instead identify which local factors interact with and determine a country's dependence on global risk appetite.

In summary, the existing literature provides evidence that both local and global/regional factors drive sovereign risk pricing. Importantly, the degree to which each of these factors matter changes over time. Our study builds on these insights and extends the existing literature by evaluating sovereign CDS spreads during COVID-19. Specifically, we examine the impact of country-specific epidemiological variables such as COVID-19 cases and mortalities on sovereign CDS spreads. Before we move on to explaining the intuition behind the epidemiological mechanisms that we test, we provide some stylized facts about COVID-19 in emerging markets.

\section{Stylized facts about emerging markets and COVID-19}

\subsection{Mortality patterns}

COVID-19 hit the global economy. However, mortality dynamics were heterogenous, both between developed and emerging countries as well as within each group. Figure 4 and Figure 5 illustrate the discrepancies in mortality rates and mortalities per million residents. As per the end of April 2020, Peru, Brazil, Panama, Romania and Turkey were the emerging market countries with the highest daily mortality rates whereas Bahrain, Qatar, Sri Lanka, China, and Thailand were at the lower end. A similar picture emerges for cumulative mortalities per million residents: by the end of April 2020, Hungary, Panama, Peru, Turkey, Romania had the highest death tolls whereas Bahrain, China, Qatar, Sri Lanka, and Thailand had the lowest ones. Some of this heterogeneity can be attributed to differing reporting standards across countries. Nevertheless, Jinjarak et al. (2020) provide evidence that the government pandemic policy interventions along with initial country characteristics such as demographics may have influenced mortality dynamics. They explore several demographic and structural features across a large sample of both advanced and emerging economies from $1 / 23 / 2020$ to $4 / 28 / 2020$ and find that with a lag more stringent pandemic policies were associated with lower mortality growth rates. Moreover, the association between stricter lockdowns and lower future mortality growth was more pronounced in countries with a greater proportion of the elderly population, greater democratic freedom, larger international travel flows, and further distance from the equator. In addition, they document that the extent to which the peak mortality rates were explained by government pandemic policies and country-specific structural features is heterogeneous. 
Crucially, the difference in mortality rates and mortalities per million residents across emerging markets provides us with variation that we can use to estimate the effect of country-specific factors on sovereign CDS spreads. Before estimating these effects, let's have a look at another source of variation: fiscal responses of emerging markets to COVID-19.

\subsection{Fiscal responses}

The fiscal response of emerging markets to COVID-19 has been decisive. Except for Saudi Arabia, all emerging markets in our sample engaged in stimulus (see Figure 3 ) and the stimulus packages include both budgetary and non-budgetary provisions. While the stimuli generally look impressive, Alberola-lla et al. (2020) point out that they are relatively modest in comparison to stimulus packages of developed countries. In fact, budgetary measures in advanced economies have reached $8.3 \%$ of GDP, 6.6 percentage points higher than in the aftermath of the great financial crisis. In contrast, for emerging markets the stimulus was on average just $2.0 \%$, which is less than in the great financial crisis. Starker than the difference in stimulus size between developed and emerging economies is how the stimulus packages are structured: The biggest difference is that credit guarantees are $6.6 \%$ of GDP in advanced economies and only $0.4 \%$ in emerging markets. The gap for funding facilities is narrower: $4 \%$ of the GDP of advanced economies versus $1.3 \%$ in the case of emerging markets. The difference in fiscal stimulus packages between advanced and emerging markets could be a symptom of a lack of fiscal space in the case of the latter. More likely, however, a potential lack of fiscal space only explains part of the difference in stimulus size. Another plausible reason may be the difference in the prevalence and severity of the pandemic between advanced and emerging economies. COVID-19 proved more lethal in advanced economies which on average have older populations that are more prone to severe symptoms of COVID-19. Lastly, another reason for comparatively smaller fiscal stimuli in emerging markets is that fiscal stimulus is a substitute to monetary stimulus: emerging markets have been able to take advantage of more room to cut policy rates than their advanced economy counterparts. At the start of 2020, policy rates in emerging markets were on average $4.9 \%$ (excluding Argentina) whereas the average policy rates in advanced economies were at $0.4 \%$. Since then, emerging markets have cut policy rates by around 114 basis points, almost three times the 40 basis points cut of advanced economies. However, Figure 6 makes it clear that rate cuts alone are no silver bullet for emerging markets. Particularly for the oil exporting countries (except for Mexico, which largely hedges oil revenues), rate cuts necessitated interventions in foreign exchange markets and the reduction of foreign reserves to stabilize currencies.

\subsection{Sovereign CDS spread changes}

Similar to the variance in mortality patterns and stimulus size across emerging markets, there is variance in sovereign CDS spreads across emerging markets (Figure 7). Interestingly, the time and cross-country variance in sovereign CDS spreads among emerging markets is more pronounced than for developed economies (Figure 8). Crucially, the variation in CDS spreads across emerging markets and across time allows us to estimate the effect of country-specific factors on sovereign CDS spreads. 
In summary, there is variation in how countries handled the pandemic in terms of public health dynamics, fiscal responses, and sovereign CDS spreads. This variation can be used to investigate how sovereign CDS spreads reacted to COVID-19, which we do in the following section.

\section{Analysis of COVID-19 dominance}

\subsection{Are sovereign CDS spread drivers time-varying?}

In this section, our primary goal is to establish if COVID-19 lead to a time-varying relationship of sovereign CDS spread determinants. We propose a two-stage econometric approach.

In the first stage, we estimate a heterogeneous multi-factor model using daily data for thirty investible emerging markets for the period January 2014 through June 2019. The explanatory variables in the model capture global and regional risk factors. In the second stage, using a synthetic control-type procedure to extrapolate the model-implied changes in CDS spreads given the realized values of the factors, we evaluate the model's out-of-sample properties for the period between July 2019 and June 2020.

Selecting this approach has two advantages. On the one hand, it allows us to evaluate the model's out-of-sample properties for a period before the pandemic. On the other hand, we can also evaluate the model's out-of-sample properties for the pandemic period. Thus, we have two distinct periods for which we can compare the model's explanatory power. This allows us to test the first proposition that the determinants of sovereign risk pricing vary across time. The economic intuition behind testing the proposition this way is as follows: If sovereign CDS spreads are predominantly driven by global/regional risk factors at all times, we would expect the model to fare similarly well for the period before and after the global outbreak of COVID-19. However, if the model fares differently across the two periods, then this would indicate that the determinants of sovereign risk pricing are time-varying, and that the importance of country-specific factors plausibly increased after the outbreak of COVID-19.

Moreover, the two-stage approach has an additional theoretical benefit: By comparing realized and predicted CDS changes, we can calculate model residuals. Doing this for the pandemic period, we can calculate "COVID-19 residuals" which can then be used to analyze the significance of a number of country-specific factors for sovereign risk pricing during the pandemic.

In what follows, we first outline the technical details of the two-stage approach and then present the results. 


\subsubsection{Data}

We use the following data:

- Sovereign Credit Default Swap spread (CDS spread). We use the daily 5-year CDS spreads reported by Eikon Refinitiv and convert the levels into daily log changes.

- Gross domestic product (GDP). We use GDP data in current \$ reported by the World Bank.

\subsubsection{Model}

In the first stage, we estimate a factor model with daily data for thirty investible emerging market sovereigns for a period of 5.5 years from January 2014 through June 2019. Investibility is defined by a country's representation in the reference index for emerging market sovereigns, the J.P. Morgan Emerging Markets Bond Index (EMBI). ${ }^{1}$ Specifically, we use the following specification:

$$
\begin{gathered}
\Delta c d s_{i, t}=\alpha_{i}+\phi_{i} \Delta c d s_{i, t-1}+\beta_{i 1} \Delta G C D S_{t}+\beta_{i 2} \Delta R C D S_{i^{\prime}, t}+\varepsilon_{i, t} \\
\operatorname{Jan} 1,2014 \leq t<\operatorname{July} 1,2019
\end{gathered}
$$

where

$$
\Delta c d s_{i, t}=\ln \frac{C D S_{i, t}}{C D S_{i, t-1}}
$$

Our outcome variable is the daily log change in the CDS spread of country $i$. Our explanatory variables include the lagged dependent variable along with two risk factors. A global factor, $\triangle G D C S_{t}$ and a regional factor $\triangle R D C S_{i^{\prime}, t}$. The global factor is constructed as the GDP-weighted average of daily log CDS changes of a group of twenty core economies; the US, Japan, and the Eurozone member states. ${ }^{2}$ It therefore captures the common component of sovereign default risk fluctuations at the global level. ${ }^{3}$ The regional factor is constructed slightly differently. First, we sort the thirty emerging markets into seven reference groups. These groups and their constituent countries can be found in Table 3. The grouping criterion is geographic clustering. The justification for this criterion is the proposition of gravity models that countries in close proximity, i.e. geographic clusters, trade relatively more with each other than partners further apart do. Because of this, countries in close proximity often have synchronized business cycles, implying similar trends for governments' expenditures and revenues. This in turn should be reflected in the pricing of sovereign risk as argued by Remolona et al. (2008).

\footnotetext{
${ }^{1}$ See Table 1 for a list of the thirty countries in the sample.

${ }^{2}$ While the Eurozone is made up of nineteen member states, our analysis includes eighteen states as CDS data for Luxemburg was not available.

3 The weighting of countries for the global factor is based on 2019 GDP [Table 2], which renders the following weights: US 53.9\%, Japan $12.8 \%$, Eurozone $33.3 \%$.
} 
Finally, the residual is defined as

(2) $\quad \Delta c r_{i t}=\Delta c d s_{i t}-\left[\hat{\alpha}_{i}+\hat{\phi}_{i} \Delta c d s_{i, t-1}+\hat{\beta}_{i 1} \Delta G C D S_{t}+\hat{\beta}_{i 2} \Delta R C D S_{i^{\prime}, t}\right]$

simply comparing the realized log CDS changes to the model-implied changes, given the true realization of the factors and lagged log CDS changes.

\subsubsection{Results and interpretation}

After training the factor model from January 2014 through June 2019 in the first stage, we extrapolate the model based on realized values of factors from July 2019 through June 2020 in the second stage. This spans time both before and after the outbreak of COVID-19. The upper-left panel of Figure 9 traces the emerging market average cumulative log CDS change (solid line) against that predicted by the model (dashed line). Note that the two lines greatly overlap between July and December 2019, implying that the model does a good job in predicting actual CDS spread changes for the period before the outbreak of COVID-19.

In early 2020, the two series start to fluctuate and the lift-off in both model-implied and actual values accelerates in March 2020. However, actual values sore considerably more than predicted, suggesting that the model loses some of its explanatory power in the wake of the pandemic. CDS spread widening ceased in mid to end of March but the divergence between actual and model-implied changes persisted. The contrast between the explanatory power before and after the start of the pandemic can be taken as evidence for a time-varying relationship of the determinants of sovereign risk pricing and hints that country-specific factors generally may have become more important determinants during COVID-19.

The lower charts of Figure 9 compare the top and bottom five mortality emerging markets by end of April 2020. The bottom-left chart indicates that the change in actual CDS values was more marked for high mortality countries than for low mortality countries. This corroborates our finding from above that country-specific risk factors are partially responsible for the spike in CDS spreads during the pandemic and it suggests that mortality dynamics may have been one of the dominant country-specific factors. The bottom-right chart indicates two things: High mortality countries experienced more volatility in their CDS spreads than their low mortality counter parts. Furthermore, the residuals for low mortality countries were positive for the whole period and turned sharply positive in March 2020, which stands in contrast to high mortality countries' residuals which turned sharply negative in March 2020 and then started to approach the low mortality residual levels by the end of June. The greater volatility for high mortality countries is additional evidence that country-specific risk factors became more important determinants of sovereign risk pricing during the pandemic. Lastly, the upperright of Figure 9 charts the cross-sectional dispersion of CDS spreads between July 2019 and June 2020. The dispersion already rose over the second half of 2019 and experienced a marked uptick in March 2020, highlighting the sharp rise in volatility and the divergent path of CDS spreads across emerging markets amid the pandemic. The 
increasing dispersion of CDS spreads across countries visualizes that the model's explanatory power decreased during the pandemic, again suggesting that countryspecific determinants of sovereign risk pricing took on a more prominent role during COVID-19.

While the top-left chart of Figure 9 indicates that the model does a good job of predicting emerging markets CDS spread changes at an aggregate level before the pandemic, this is not the case for all countries individually: For some countries both the $\mathrm{R}$-squared in the estimation period as well as the predictive accuracy out-of-sample are relatively low (see columns 5 and 6 in Table 4). This in itself does not invalidate our twostage approach. If anything, it supports the proposition that the determinants of sovereign risk pricing are time-varying at the level of individual economies, too. However, including countries for which the model performs subpar in the period before the pandemic would lead to distortions in our later analysis of residuals. The reason for this is simple: If we included countries for which the model does not work well before the pandemic, we would potentially attribute residuals to the pandemic even though they already existed before it (see Figure 10 for such cases). Therefore, we drop countries for which the global/regional model does not work well from the sample. We choose a correlation coefficient between actual and fitted values for the period between July 2019 and February 2020 below 0.25 as the cut-off value. This results in a reduced sample of twenty emerging markets, which we list in Table 5. A possible concern with this procedure is that by trimming the ten outlier countries from our sample we reduce the veracity of our main results. We deal with this concern in Section 4.4 , where we show that our results, including the relative importance of economics versus epidemiology news, hold for the entire sample of 30 countries in a single regression analysis of daily CDS spread during January 2014 to June 2020.

\subsection{Which country-specific factors drove CDS spreads during COVID-19?}

In the previous subsection we established that the global outbreak of COVID-19 lead to a time-varying relationship of the determinants of sovereign CDS spreads and that country-specific factors in general became more prominent. In this section, our primary goal is to identify exactly which country-specific factors drove CDS spreads during the pandemic.

We begin by defining three COVID-19 subperiods: Early COVID-19 (January-February 2020), peak COVID-19 (March 2020), and late COVID-19 (April-June 2020).

By defining three COVID-19 subperiods, we document that March 2020 is the period during which the realized values of daily CDS spread changes diverged the most from model-implied values. In contrast, the global/regional factor model does an excellent job of tracing realized values before and after that (see Figure 11). Furthermore, we observe that daily CDS spread changes were remarkably higher and more volatile in March 2020 than in the early and late COVID-19 periods (see Figure 9). As such, we focus on the peak COVID-19 period to evaluate which country-specific factors account for the variation in CDS adjustment that is not explained by the model. 
Clearly, there's a myriad of country-specific factors that could potentially affect CDS spreads during peak COVID-19. However, neither are all of these factors equally plausible nor can all of them be tested due to data limitations. As such we identify a number of country-specific factors that could plausibly influence sovereign risk pricing and group them into three categories: economic variables, policy responses, and epidemiological variables.

The economic intuition behind including country-specific economic variables builds on insights of Kocsis \& Monostori (2016) and Ahmed et al. (2017): Variables that determine government revenues and expenditures help explain government solvency and thus the pricing of sovereign risk. We propose seven economic variables:

- an economy's dependence on oil prices, which determine directly and indirectly a sizeable share of government revenues for many emerging markets

- an economy's access to the IMF's Rapid Financing Instrument, which could alleviate temporary liquidity problems and avoid defaults

- an economy's access of Fed swap lines, which could alleviate temporary liquidity problems and challenges related to foreign denominated debt

- sovereign wealth fund buffers and international reserve buffers, which could be used to stabilize the exchange rate

- external debt ratios, which indicate an economy's vulnerability to external funding conditions and exchange rate swings

- an economy's ratio of (hidden) debt owed to China, which indicates an economy's vulnerability to exchange rate swings that may not be captured by official numbers on external debt ratios

The economic intuition behind including policy variables builds on the idea that policy responses such as fiscal stimuli lead to higher deficits and higher future sovereign debt burdens. This in turn may increase the expected likelihood of sovereign defaults and affect sovereign risk pricing. We propose three policy variables:

- dummy variables that indicate the date of country-specific key fiscal policy announcements

- dummy variables of key policy announcements by the European Central Bank

- dummy variables of key policy announcements by the US Fed

The economic intuition behind including epidemiological variables builds on two ideas. On the one hand, some epidemiological variables are proxying for GDP. Thus, they capture potential income falls which affect government tax revenues as well as expenditures through fiscal stimulus. On the other hand, epidemiological variables like accelerated COVID-19 mortality also capture the pandemic trend, possibly impacting the speed of future recovery as well as the severity of longer-term output losses due to bankruptcies, degradation of human and physical capital, and other social costs. We propose three such variables:

- a variety of variables related to mortality: the daily new mortality rate per $1,000,000$ population and the daily new mortality growth rate, the cumulative mortality rate per $1,000,000$ population and the cumulative mortality growth rate. 
- daily growth rates of policy stringency indices, which indicates to what extent governments hindered the free functioning of the economy and thus proxies for economic activity

\subsubsection{Data}

Specifically, we use the following data and variable definitions:

- Deaths. We use daily deaths per country reported by the Center for Systems Science and Engineering at Johns Hopkins University (JHU CSSE). Counts include confirmed and probable where reported.

- Stringency Index SI. We use the Oxford COVID-19 Government Response Tracker which measures the strictness of lockdown policies that primarily restrict people's behavior.

- ECB Policy Dummy. Fed Policy Dummy. Fiscal Policy Dummy. Daily fiscal and monetary policy announcements. These were collected for individual countries, for the European Central Bank, and for the Federal Reserve. These columns capture whether or not an action or proposal was made by a given institution/country on a specific date. A row is coded as " 1 " if the date corresponded with the announcement of at least one key policy. With the exception of the Federal Reserve (whose major announcements related to reductions in the interest rate along with fiscal spending), we restricted our analysis of key fiscal policies to those which provided "millions" or "billions" of local currency units in spending. The drawback is that this measure does not show the size or number of policies on any given day. However, such a measure is not available on a consistent basis across countries. ${ }^{4}$

- External Debt. We use the total external and private sector debt stock as a share of GDP as reported by the World Bank. The data is yearly.

- Debt owed to China. We use the estimated total external debt stock owed to China in current USD as a share of the debtor GDP as reported by Horn et al. (2019). The data is reported yearly up to 2018 so that we used the most recent yearly values for crosscountry variance.

- Oil price income effect. This is a compound variable that is calculated daily as: Daily Oil price * [(Oil share of exports * Export share of GDP) - (Oil share of imports * Import share of GDP)]. The daily oil price data is for Brent as reported by Eikon Refinitiv. The data for export and import shares of GDP are from the World Bank. The data for oil export and import shares are from the International Trade Center (ITC).

- International reserves. International reserves in current USD as reported by the IMF. Data is monthly.

- Sovereign Wealth Fund Volume. Sovereign wealth fund volume in current USD as reported by PWC. Data is yearly.

\footnotetext{
4 The primary data sources used to construct these policy announcement variables are: Yale COVID-19 Financial Response Tracker; Harvard Global Policy Tracker; Bruegel COVID-19 National Dataset; IMF Policy Responses to COVID-19; and the St. Louis Federal Reserve.
} 
- Rapid Financing Instrument. Approved rapid financing instrument from the IMF as share of recipient country's GDP. ${ }^{5}$

- Swap line activation. Measures the activation of a swap line with the Fed. Data is from Bahaj \& Reis (2020). ${ }^{6}$

\subsubsection{Model}

Including these variables and using the peak COVID-19 residual from (2) as the dependent variable results in the following model where $\vartheta_{i}$ and $\lambda_{t}$ represent country and time fixed effects, respectively:

$$
\begin{gathered}
\Delta c r_{i t}=\vartheta_{i}+\lambda_{t}+\theta X_{i, t}^{\text {COVID }}+\gamma X_{i, t}^{\text {economy }}+\eta X_{i, t}^{\text {policy }}+\epsilon_{i, t} \\
\text { March 1,2020 } \leq t \leq \operatorname{March~31,2020}
\end{gathered}
$$

\subsubsection{Results and interpretation}

The results of (3) are reported in Table 6. Daily new mortality rates and new mortality growth rates are positively associated with COVID-19 residuals across all three specifications, although not statistically significantly so. Specifically, countries that saw higher new mortality rates or higher new mortality growth rates were likely to see wider divergence in realized CDS spreads from model-implied values. The cumulative mortality rate and its growth rate are negatively related to the COVID-19 residuals and the growth rate becomes statistically significant when adding the economic and policy variables. While the mortality and mortality growth rates together only explain a small share of the variation in COVID-19 residuals (R-squared of 1.24\%), adding the other COVID-19 specific variable (growth of policy stringency index) increases the R-squared to $1.37 \%$. This suggests that the economic ramifications directly related to lockdowns account for a relatively minor share of CDS adjustment and is smaller than the mere thought about additional future lockdowns that could be indicated by mortality dynamics. In contrast, a bigger jump occurs when we include policy responses and economic variables so that we reach an R-squared of roughly $6.47 \%$. In specifications 2 and 3 we also see that the SI growth coefficient is not statistically significant. The interpretation is that the growth of policy stringency - as an ad-hoc measure of daily economic activityhas little effect on CDS residuals. This suggests that sovereign risk pricing during peak COVID-19 has been predominantly driven by traditional country-specific economic variables. ${ }^{7}$

\footnotetext{
${ }^{5}$ Because no RFI was announced/approved in March 2020, this variable will not show up in the regression tables.

${ }^{6}$ Facing visible strain in dollar funding markets during the COVID-19 pandemic, the Fed lowered the rate on the swap lines it had with five other central banks, and opened new ones with nine other countries on 19 March 2020: Australia, Brazil, Mexico, Denmark, South Korea, Norway, New Zealand, Singapore, and Sweden. As of 31 March 2020, only the central banks of Sweden, Norway, Denmark and Singapore were have completed a dollar swap line operation. Thus, no emerging market country has accessed a swap line so this variable will not show up in the panel regression.

${ }^{7}$ In a previous version of the paper, we estimated additional specifications as a robustness check and results are available upon request. A brief summary: We augmented specification 3 with mobility data as
} 
While two out of three policy measures, i.e. Fed policy dummy and as well as interaction terms with country-specific fiscal policies, don't have statistically significant associations with COVID-19 residuals, the interaction of the fiscal policy dummy with the external debt level is nevertheless positive, indicating that countries that increased their debt burdens through stimuli or countries that already had relatively high debt burdens to begin with were likely to see larger spread increases. Equally, more (hidden) debt owed to China is also positively associated with CDS residuals, albeit again not statistically significantly so. However, the interaction of debt owed to China with the fiscal policy dummy is negatively correlated with residuals. This seems to indicate a somewhat indifferent view of investors about the fiscal sustainability of announced stimuli, which can probably be partially explained through the fact that some financial market participants are not aware of the (hidden) debt that countries owe to China. Lastly, the coefficient of the oil income effect indicates that reductions in oil prices are positively correlated with peak COVID-19 residuals. A finding worth pointing out is that the $F$ statistic of all three specifications is not statistically significant. Thus, we cannot reject the null that any of the groups of COVID-19 variables (economic, epidemiological or policy) are jointly insignificant. However, the statistical insiginificance of many of the coefficients individually as well jointly are not contradictory to our theoretical expectations. Indeed it is important to acknowledge that most coefficients take on the expected sign. This implies that the statistical insignificance of the results mainly comes from the relatively low degrees of freedom which in turn is the result of the short estimation window (March 2020), data unavailability for some country-variable combinations, and the use of time and country fixed effects. However, we show similar results over a longer period of time in section 4.4. Figure 12 provides a graphically summary by showing the economic significance of variables based on specification 3 of Table 6. The length of each bar is the product of the variable's sample standard deviation with its coefficient estimate. The figure confirms that it is mostly traditional economic determinants of sovereign risk pricing that influenced residuals in March 2020.

\subsection{Did country-specific or global factors dominate CDS spreads during COVID-19?}

So far, the analysis uncovered that during COVID-19 global/regional risk drivers only partly explained CDS adjustments. We also showed that traditional factors such as the oil price effect and existing levels of sovereign debt are the country-specific factors which particularly help explain CDS adjustments in March 2020. However, we can extend the analysis by asking to which degree global/regional factors and countryspecific ones more generally played a role in the CDS adjustment during peak COVID-

\footnotetext{
a proxy for economic activity. Mobility's positive coefficient was statistically significant and the model's Rsquared increased to $19.25 \%$. However, economic intuition would suggest that higher mobility (i.e. more economic activity) would gernally be associated with with smaller residuals during peak COVID-19, not larger ones. The unexpected sign may be related to non-linearities and threshold effects in the relationship between mobility and economic activity, idenfitied by Nouvellet et al. (2021). They found evidence of decoupling of transmission and mobility following the relaxation of strict control measures for $80 \%$ of countries. This suggest that over the course of the pandemic the relationship between mobility and economic activity broke down, which supports removing mobility from the model.
} 
19. To address this question, we compare the explanatory power of the global/regional factors to the explanatory power of country-specific variables.

\subsubsection{Model}

Specifically, we treat realized log changes in CDS spreads as the outcome variable and explain it through the model-implied values from (1) along with country-specific explanatory variables as in (3). This results in the following model:

$$
\begin{gathered}
\Delta c d s_{i, t}=\vartheta_{i}+\lambda_{t}+\Gamma \widehat{\Delta c d s_{l, t}}+\theta X_{i, t}^{\text {COVID }}+\gamma X_{i, t}^{\text {economy }}+\eta X_{i, t}^{\text {policy }}+\epsilon_{i, t} \\
\text { March 1,2020 } \leq t \leq \operatorname{March} 31,2020
\end{gathered}
$$

where

$$
\widehat{\Delta c d s_{l, t}}=\hat{\alpha}_{i}+\hat{\phi}_{i} \Delta c d s_{i, t-1}+\hat{\beta}_{i 1} \Delta G C D S_{t}+\hat{\beta}_{i 2} \Delta R C D S_{i^{\prime}, t}
$$

are the model-implied values of the daily CDS spread changes.

Essentially, in (4) we take apart the two components that make up the residual. This way, it becomes obvious that the regression in (3) with the residual as an outcome variable is equivalent to the regression in (4) when we restrict $\Gamma=0$. Crucially, we don't impose this restriction, which lends to a richer analysis of the relative contribution of CDS adjustments made by global/regional and country-specific drivers.

\subsubsection{Results and interpretation}

The results of (4) are reported in Table 7. First, note that in specification 1 the coefficient for the fitted daily CDS spread change is highly statistically significant and of considerable magnitude. Specifically, a one percentage point increase in the CDS spread changes as predicted by the global/regional factor model alone is associated with approximately a 0.57 percentage point change of actual CDS spreads. This makes intuitively sense as we would expect global/regional factors to continue driving spreads during peak COVID-19. After including economic, policy, and epidemiological variables in specification 3, the coefficient of model-implied values remains statistically significant and its magnitude increases to approximately 0.6. This implies that once we control for country-specific drivers of spreads, there is a relatively strong association of global/regional spread changes and the changes of an individual country, meriting the model selection in the first stage.

Second, adding mortality variables in specification 2 only increases the explanatory power of the model from $4 \%$ to $6.9 \%$. Intuitively, we would expect that higher mortality growth rates would indicate higher CDS spreads, all else equal, but the coefficient on the cumulative mortality growth rate is negative. However, none of the mortality variables are statistically significant. Presumably, this is the result of confounding variables that are not controlled for in specification 2. 
Third, adding the remaining country-specific variables to the model increases the explanatory power considerably to more than $10.5 \%$ in specification 3 , even though a majority of variables are not statistically significant individually. However, this is again unsurprising given the low degrees of freedom which is due to the short length of the panel, fixed effects, and data unavailability.

Lastly, interaction terms with announcements of fiscal responses are insignificant, both statistically and in their economic magnitude. This indicates that neither the presence of such announcements nor the existence of higher external debt burdens significantly increased the perceived risk. This result is interesting: even governments with higher external debt levels or large and potentially unsustainable stimuli were able to get away with it for now. This suggests a form of "COVID-19 dominance" at the height of the pandemic in that investors primarily worried about the effects of an immediate economic drop rather than the longer-term effects of higher debt burdens.

In summary, the results above suggest that country-specific variables generally were the more dominant drivers of CDS spread adjustments during peak COVID-19 than global/regional factors. Including country-specific factors increases the explanatory power of the model from less than $4 \%$ to more than $10.5 \%$, which is a relatively high value for high-frequency macro-financial regressions. Of the country-specific variables, economic factores seem to be the more important drivers of spread changes than epidemiological ones. ${ }^{8}$

\subsection{Does COVID-19 mortality affect CDS spreads after controlling for immediate economic ramifications of the pandemic?}

So far, our analysis has only tangentially addressed the question whether the epidemiological severity affected CDS spreads once the economic challenges through lockdowns as well as declining oil prices are taken into account. To tackle this question, we use a panel which is consistent with (4) but over a longer stretch of time. Hence, it also uses global/regional and country-specific factors to explain CDS spreads but it covers the entire period between January 2014 and June 2020.

The analytical appeal behind the proposed empirical strategy is evident: Choosing a panel estimator that explains CDS spread changes through global/regional and countryspecific factors-particularly epidemiological factors-allows us to test the significance of the independent effect of mortality dynamics on spreads. If there is no independent effect of mortality on spreads, then this would suggest that there is no "pandemic effect." In other words, the entire adjustment of sovereign risk pricing over the course of the pandemic would be attributed to traditional economic drivers. However, if we observe a significant effect of mortalities on spreads, then this opens up two interpretations, depending on the sign of the coefficient.

\footnotetext{
${ }^{8}$ We also estimated specification 3 of Table 7 with an added mobility variable. Including it increases the R-squared to $21.16 \%$. While all coefficients except the one for SWF/GDP keep its signs, many become statistically significant. However, the highly statistically significant coefficient of mobilty again takes on a positive sign, which isn't in line with a priori expectations.
} 
One interpretation of a positive association of mortalities and spread changes could be that investors are concerned about intensifications or extensions of lockdowns. The economic intuition: Higher mortality numbers may engender longer or more stringent lockdowns which would increase the need for additional stimulus and the debt burden and thus the likelihood of sovereign default.

In contrast, a negative association could be interpreted as a positive productivity shock in the eyes of financial market participants. Specifically, economies with relatively high numbers of mortalities will need to spend relatively less of their productive resources on the elderly in the medium to longer term. This would alleviate strains on government finances caused by health and retirement expenses, lowering the expected probably of sovereign default. While this may seem like a morally reprehensible interpretation, the economic argument draws on a paper by Young (2005) with the provocative title "The Gift of the Dying: The Tragedy of AIDS and the Welfare of Future African Generations." This paper identifies two competing effects of the AIDS epidemic. On the one hand, it finds that the epidemic has a detrimental impact on human capital accumulation of orphaned children as their education is permanently interrupted at the time of their parents' death. On the other hand, it finds that widespread community infection lowers fertility through both a reduction in the willingness to engage in unprotected sexual activity and by increasing the scarcity of labor and hence the value of a woman's time. The study concludes that the fertility effect dominates even under the most pessimistic assumptions concerning reductions in educational attainment. Thus, AIDS is an example of a viral disease that despite bringing immeasurable horror upon people may have had some positive long-term economic effects on future generations. As COVID19 primarily affects older generations, a somewhat similar mechanism may unfold: Specifically, it may be that the relative shrinking of older generations may lead to reduced strains on government budgets and lowered expected probabilities of sovereign default.

\subsubsection{Model}

We use the following model that combines global/regional and country-specific factors to address the question whether and how mortalities affect CDS spreads:

$$
\begin{gathered}
\text { (5) } \Delta c d s_{i, t}=\phi_{i} \Delta c d s_{i, t-1}+\beta_{i 1} \Delta G C D S_{t}+ \\
\beta_{i 2} \Delta R C D S_{i^{\prime}, t}+\theta X_{i, t}^{C O V I D}+\gamma X_{i, t}^{\text {economy }}+\eta X_{i, t}^{\text {policy }}+\vartheta_{i}+\epsilon_{i, t} \\
\text { January } 1,2014 \leq t<\text { July } 1,2020
\end{gathered}
$$

\subsubsection{Data modifications}

While we can generally use the same data and variables that we introduced in section 4.2.1 and used to estimate (4), some modifications are necessary. This is to account for the fact that the reporting of some variables only begins in 2020 while we need them for January 2014 to June 2020. Specifically, we make the following modifications for 
COVID-19 case and mortality numbers: COVID-19 epidemiological measures such as daily cases and mortalities and their growth rates are backfilled with the number "0" for all observations before January 22, 2020. The intuition behind this is that the JHU CSSE COVID-19 reporting begins on January 22, 2020. Thus, it is innocuous to assume that prior to that date there were no (known) COVID-19 cases or mortalities.

\subsubsection{Results and interpretation}

The results of (5) are reported in Table 8. Let's first look at specification 1 which is essentially model (1) but over a longer period that covers the pandemic. All three coefficients are highly statistically significant, their signs are as expected, and the model has notable explanatory power with an R-squared of $20.26 \%$. Specifically, the lagged CDS change has a negative sign, which indicates a mean reverting process and the positive signs of the global and regional factor indicate positive relationships of CDS spreads across the globe. Also note that a one percentage point increase in CDS spreads of the core countries (USA, Japan, and Eurozone countries) is associated with a 2.3 percentage point increase in emerging markets. This suggests that increases in CDS spreads of the global economy's core countries have a magnifying effect on emerging markets (along the line of "when the core sneezes the rest of world catches a cold"). There is also a positive relationship between an emerging market's CDS spread and the spreads of its regional peers which may indicate some form of regional economic contagion and dependence. This effect also remains significant when we construct the regional factor differently in specification 2 . There, we investigate how CDS spreads co-move with the spreads of all emerging market peers when we use bilateral trade shares as the weights to construct the factor instead of using GDPs of local regional peers as the weights.

Now that we have established that the simple global/regional factor model does a good job at modeling CDS spreads over this longer period, let's look at specification 3 which shows the results of a panel estimator consistent with model (4).

First, note that the first three coefficients all remain highly statistically significant and barely change in magnitude when compared to the global/regional model. Also, consider Figure 13 that shows the products of the estimated coefficients and the standard deviations of the variables and suggests that the global and regional factors remain dominant factors after adding country-specific factors. Interestingly, note that both ratios of international reserves/GDP and external debt/GDP are not significant over the duration of the longer panel. This may surprise at first as one would expect that higher debt ratios would lead to higher CDS spreads and vice versa for reserve ratios. However, this finding is in line with the relative insignificance of these variables for the peak COVID-19 period and it may be reconciled further by pointing out that both these variables are relatively slow moving so that the country fixed-effects already swallow some of the cross-country variance.

Second, note that SI growth is statistically significant and shows the expected sign: Economic intuition would suggest that to fight off the pandemic, more sever restritions 
needed to be put in place in some countries. This then hinders public life, afflichts GDP and increases spreads. However, the magnitude of the coefficients is relatively small. For example, a one percentage point increase in the growth of $\mathrm{SI}$ is associated with an increase in CDS spreads of 0.46 percentage points.

Third, the coefficient for the fiscal response dummy interacted with stimulus size as a share of GDP is positive and statistically significant. This is consistent with economic intuition in two ways: In the medium to long run, comparatively bigger stimulus packages add to the future debt burden. This increases the expected likelihood of default and pushes CDS spreads up. In the short run, investors may consider higher stimulus packages as a signal of a relatively more severe economic crisis and as such start asking questions about debt sustainability, which pushes up CDS spreads. At the same time, the magnitude of this coefficient is considerable: it suggests that a one percentage point increase in stimulus is associated with approximately a 2.3 percentage point increase in spreads. However, we should keep in mind the relatively narrow distribution of the size of fiscal packages which becomes visible when we multiply the coefficient with the standard deviation of the variable in the sample (see Figure 13). This relatively small product shows that the stimulus packages on their own are not a main driver of spreads over a longer period.

Next, consider the coefficient for the growth of the cumulative mortality rate. It is statistically significant and shows that a one percentage point increase in the growth rate of the cumulative mortality rate is associated with an increase in spreads of about 0.84 percentage points. Considering that it shows the detrimental effect on spreads after the immediate effects of the economic downturn resulting from lockdowns and the effects of lower oil prices have been taken into account, the effect is of considerable magnitude and suggests that investors closely monitor COVID-19 mortality numbers, making mortalities a temporary focal point during the pandemic. There are a number of complementary interpretations of the positive association: One interpretation is that investors are concerned about imminent intensification of lockdowns, which would strain sovereign budgets and increase spreads. Another interpretation of the positive relationship is that investors are worried about longer-term consequences of the pandemic; either they worry that it leads to sub-trend growth for a longer time because of prolonged lockdowns or they worry that the pandemic will ultimately lead to increased bankruptcies, degradation of human and physical capital, and other social costs, all slowing GDP recovery. Ultimately, why and how exactly mortalities drive spreads once economic drivers are accounted for remains an empirical question for now and only time and the future availability of additional data will allow a more nuanced interpretation.

Lastly, a comparison of Table 6/Figure 12 with Table 8/ Figure 13 shows that the main results of the paper, including the relative importance of economic variables versus epidemiological variables, hold for the entire sample of 30 countries in a single regression analysis of daily CDS spread changes during January 2014 to June 2020. 


\section{Conclusions}

Understanding the effect of COVID-19 on emerging market sovereigns is critical given previous debt crises and the enormous pressure that the pandemic puts on sovereign finances. In light of this, this paper analyses the drivers of sovereign CDS spreads of thirty emerging market sovereigns. Our main findings can be summarized in five points: First, a model that uses global/regional factors to model spread changes traces the realized spread changes well for the period before the pandemic. This observation suggests that emerging market spreads are driven largely by global/regional factors in risk-on environments.

Second, the relationship between actual spread changes and their changes predicted by the factor model breaks down during the pandemic. This suggests that spread determinants are of time-varying nature and that investors weigh country-specific factors more heavily in their decision-making process in risk-off environments. Third, actual spread changes experience the biggest deviations from model-implied values in March 2020, suggesting that uncertainties around ramifications of the pandemic were highest at the peak of the first wave.

Fourth, spreads at peak COVID-19 (March 2020) were primarily driven by traditional country-specific factors of sovereign solvency such as fiscal space and oil income dependence rather than epidemiological policies and dynamics. This suggests, maybe surprisingly, that the severity of the pandemic in terms of mortalities in a specific country didn't influence investors' behavior much, at least not during peak COVID-19.

Fifth, over the entire pandemic period, however, the growth in the cumulative mortality rate is significantly positively associated with CDS spread changes after taking the economic ramifications of lockdowns and the oil price decline into account. This suggests that investors either feared a near-term intensification of lockdowns or a longer-term continuation of lockdowns, and possibly a slower GDP growth recovery. 

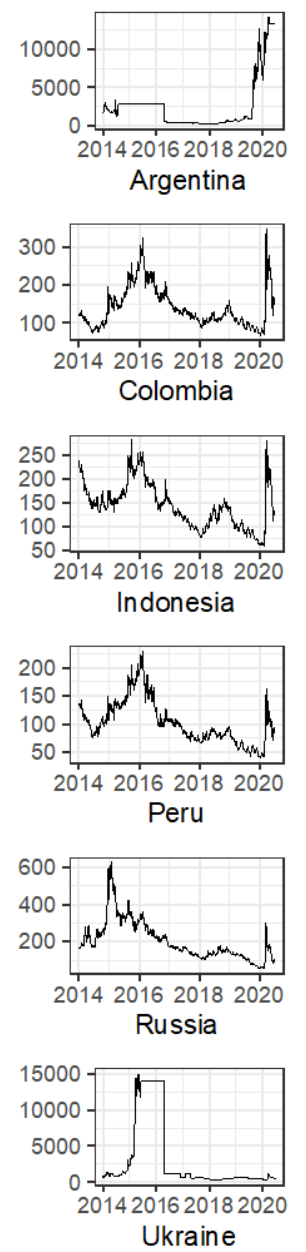
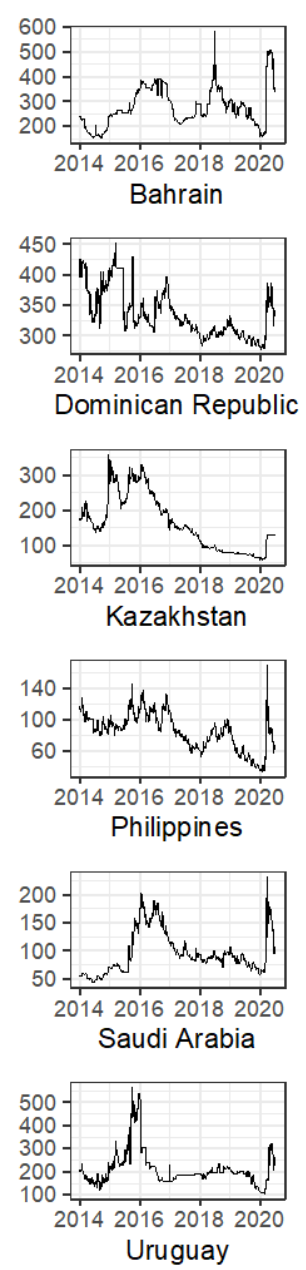
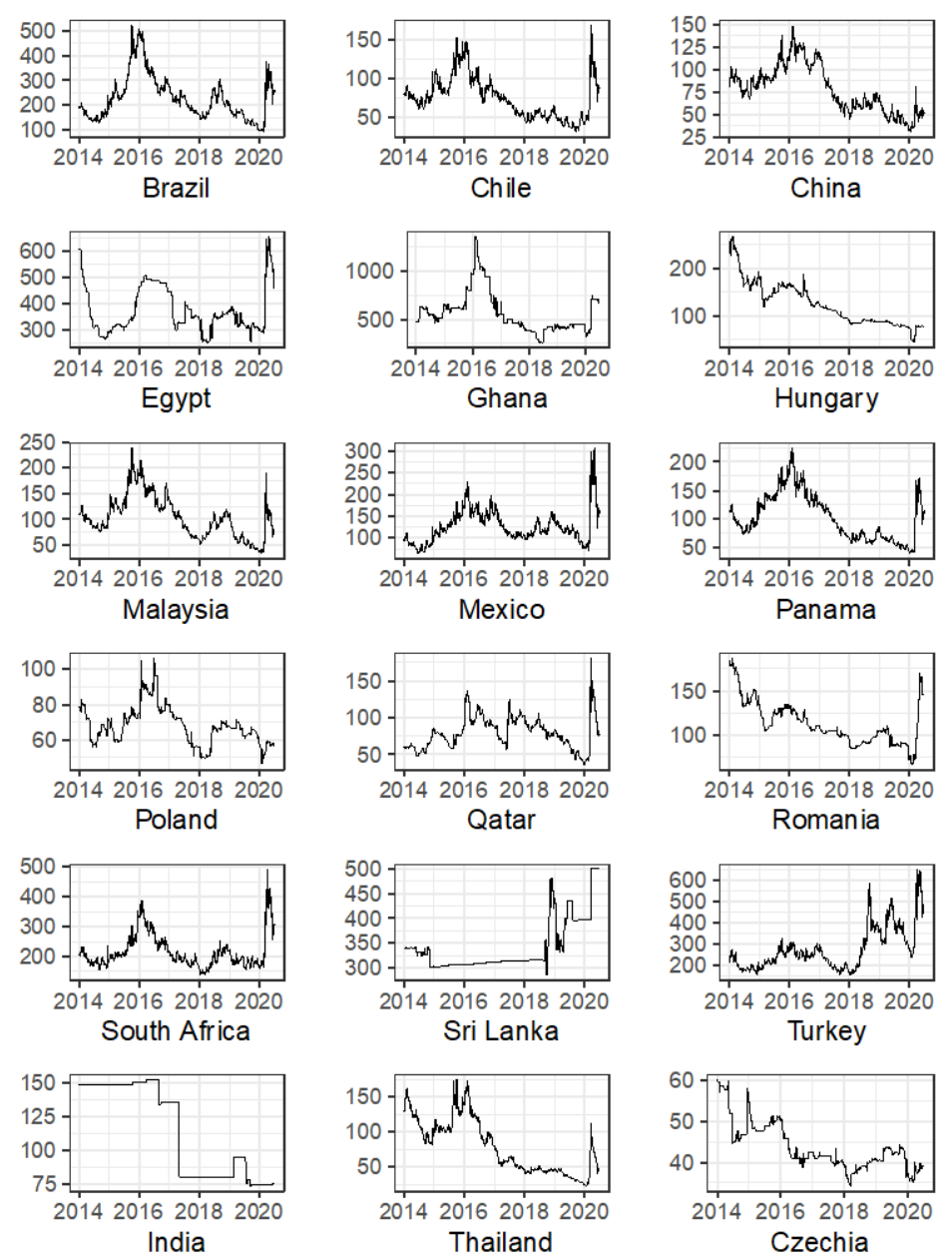
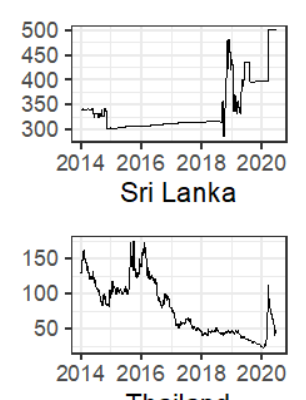

Thailand
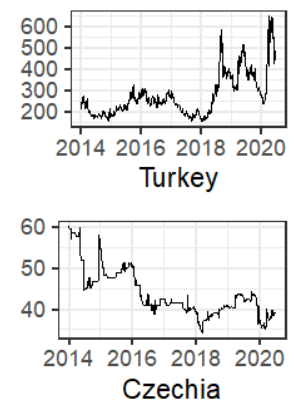

Figure 1: 5-year sovereign CDS spreads of emerging markets, January 2014 - June 2020.

Data source: Eikon Refinitiv.

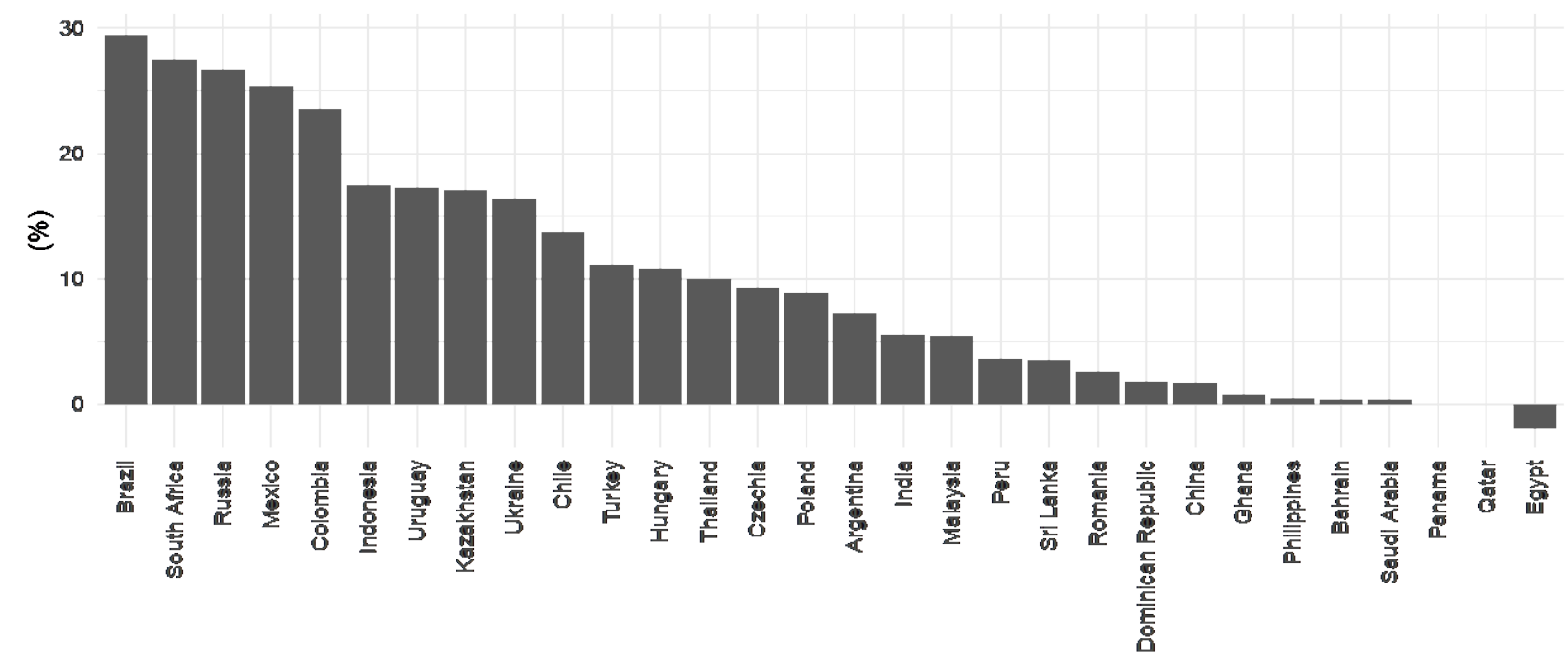

Figure 2: Changes in exchange rates of emerging markets against the US Dollar between January and March 2020. Positive values indicate a weakening of the currency. Data source: Eikon Refinitiv. 


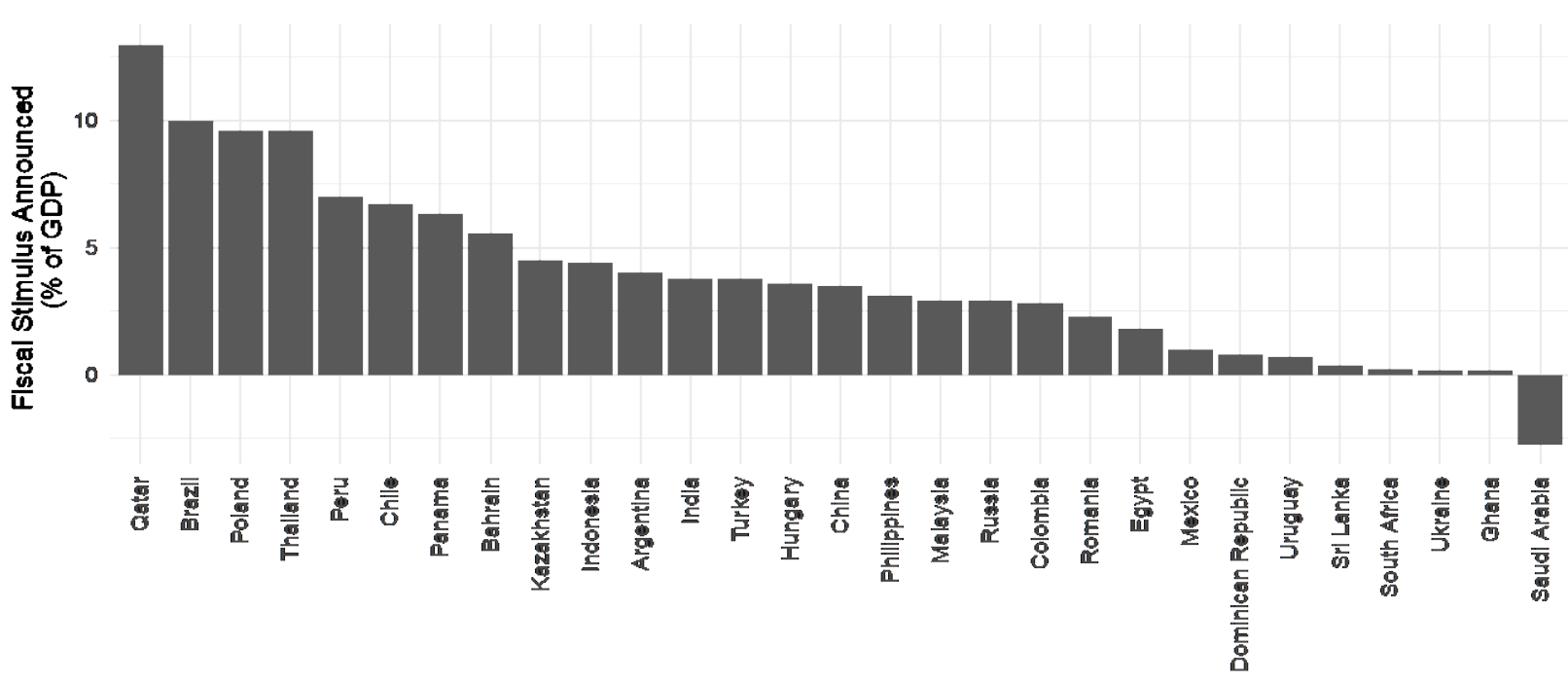

Figure 3: Announced 2020 COVID-related fiscal stimulus of emerging market countries. COVID-19 fiscal stimulus data taken from the IMF COVID policy tracker.

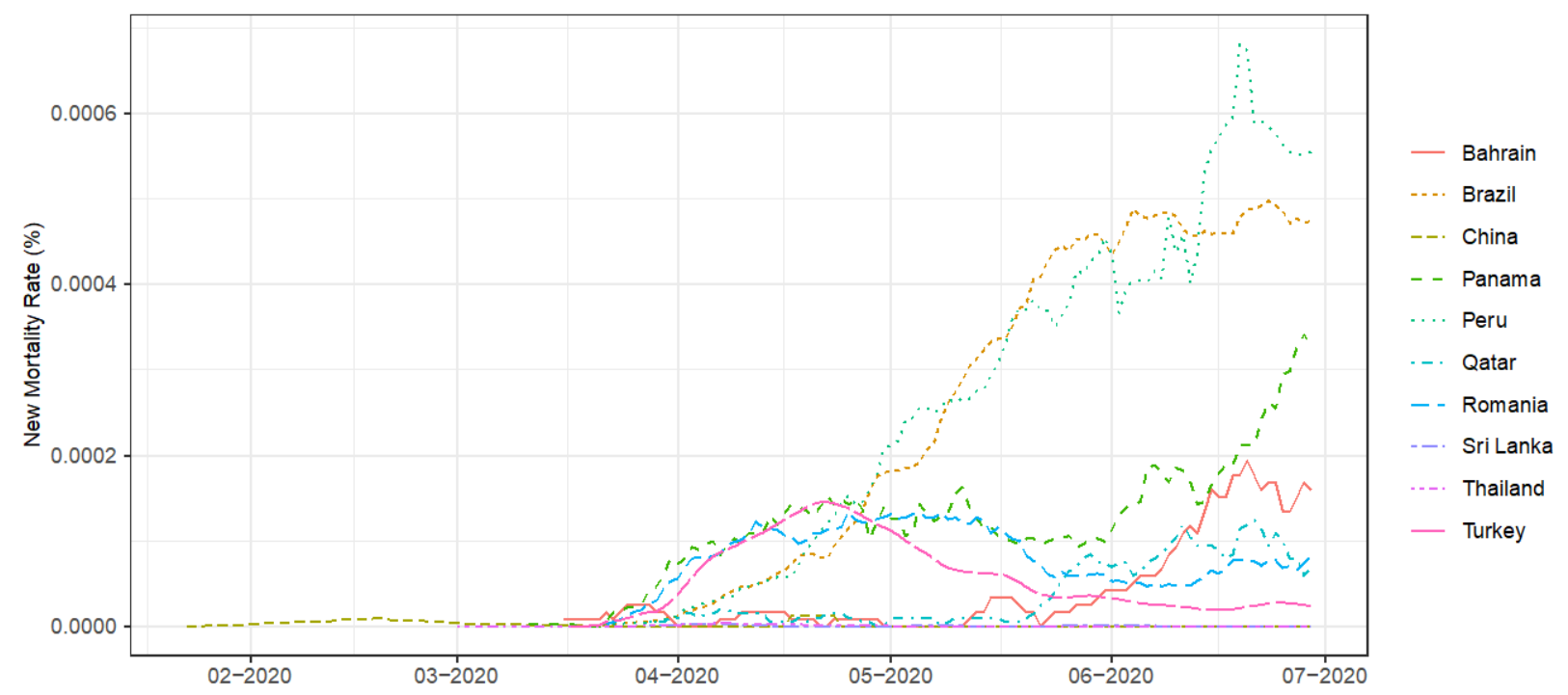

Figure 4: COVID-19 mortality rate curves for the top and bottom five emerging markets as per the end of April 2020 (based on 30 country sample). New mortality rate as 7-day rolling averages. Data source: JHU CSSE. 


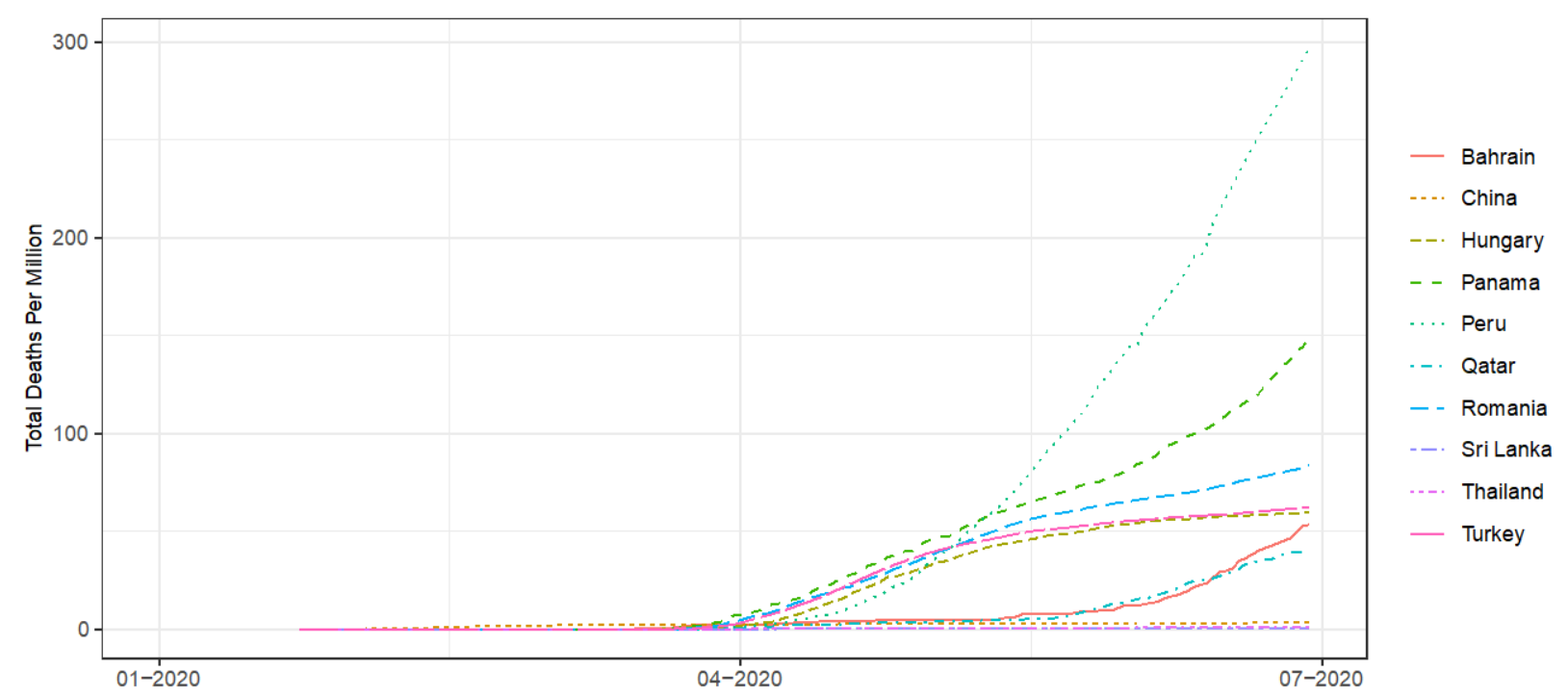

Figure 5: COVID-19 deaths per million residents for the top and bottom five emerging markets as per the end of April 2020 (based on 30 country sample). Data source: JHU CSSE.

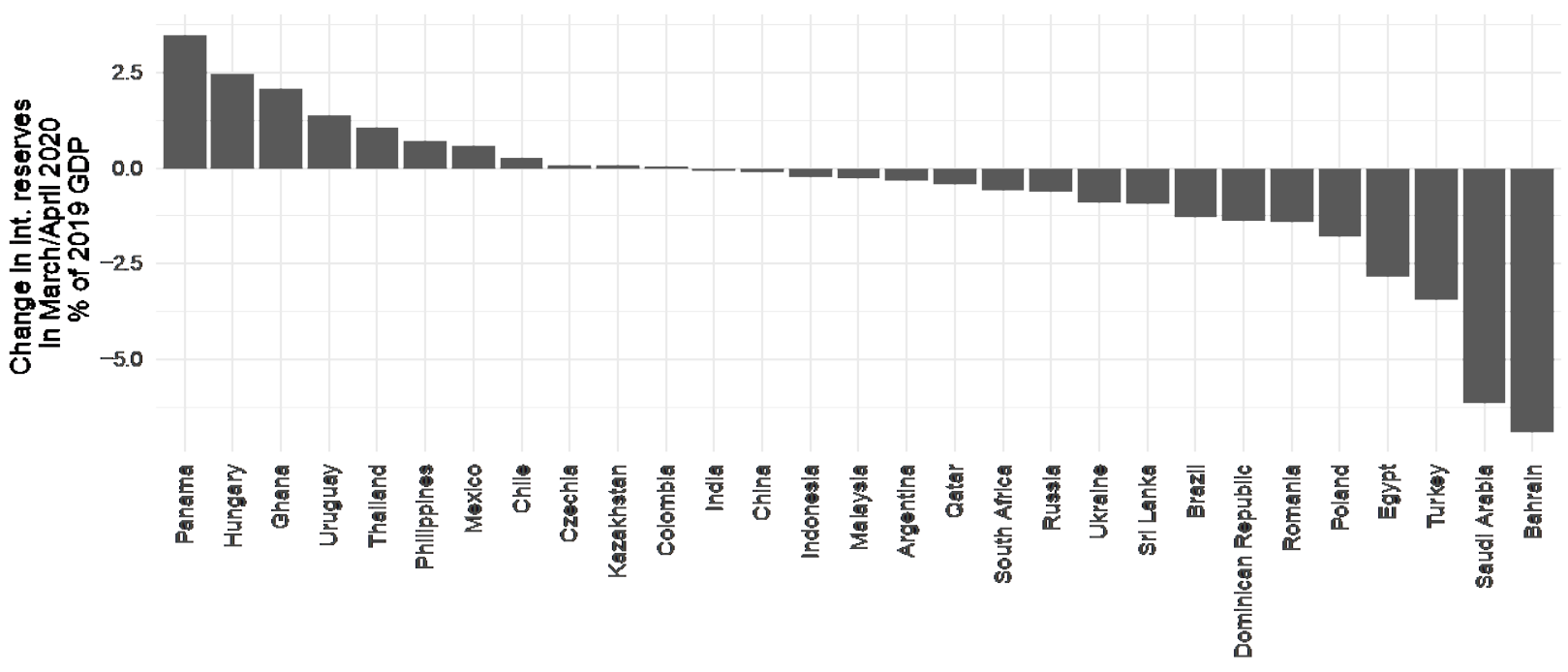

Figure 6: Change in international reserve holdings of emerging markets between March and April 2020 as a share of 2019 GDP. Data source: IMF. Peru not pictured due to data unavailablility. 

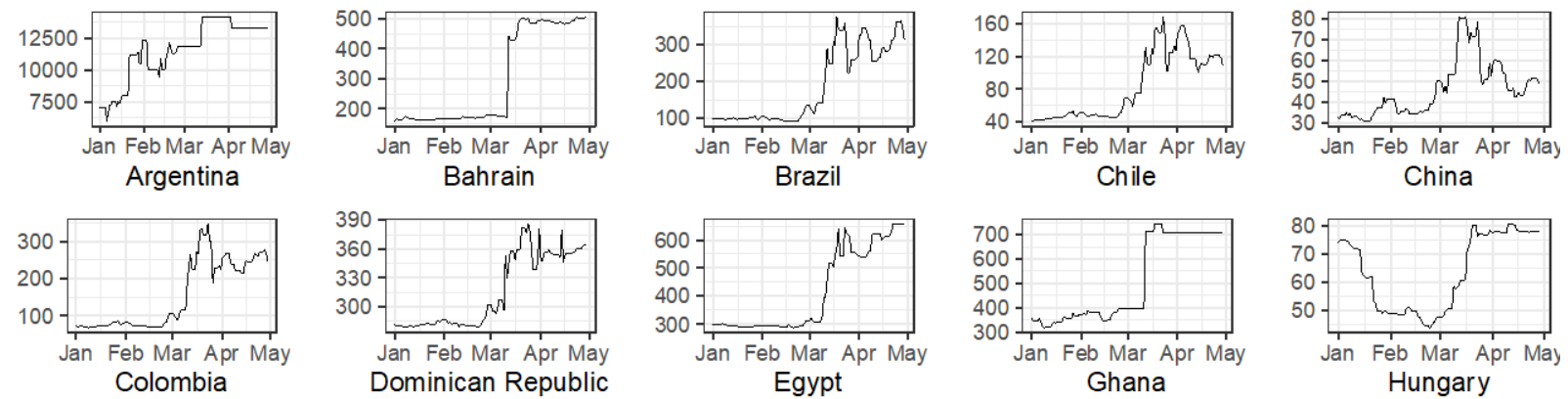

China

Colombia
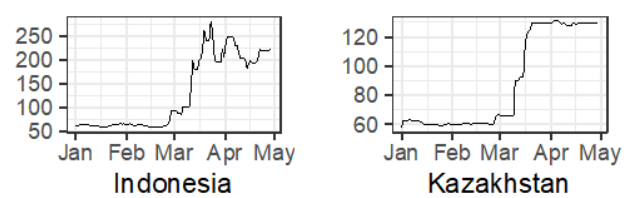

Egypt
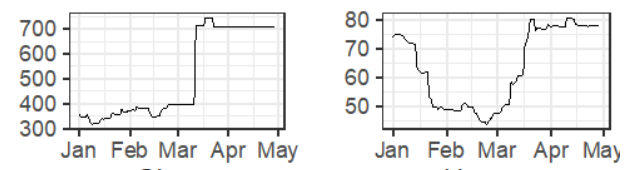

Ghana

Hungary
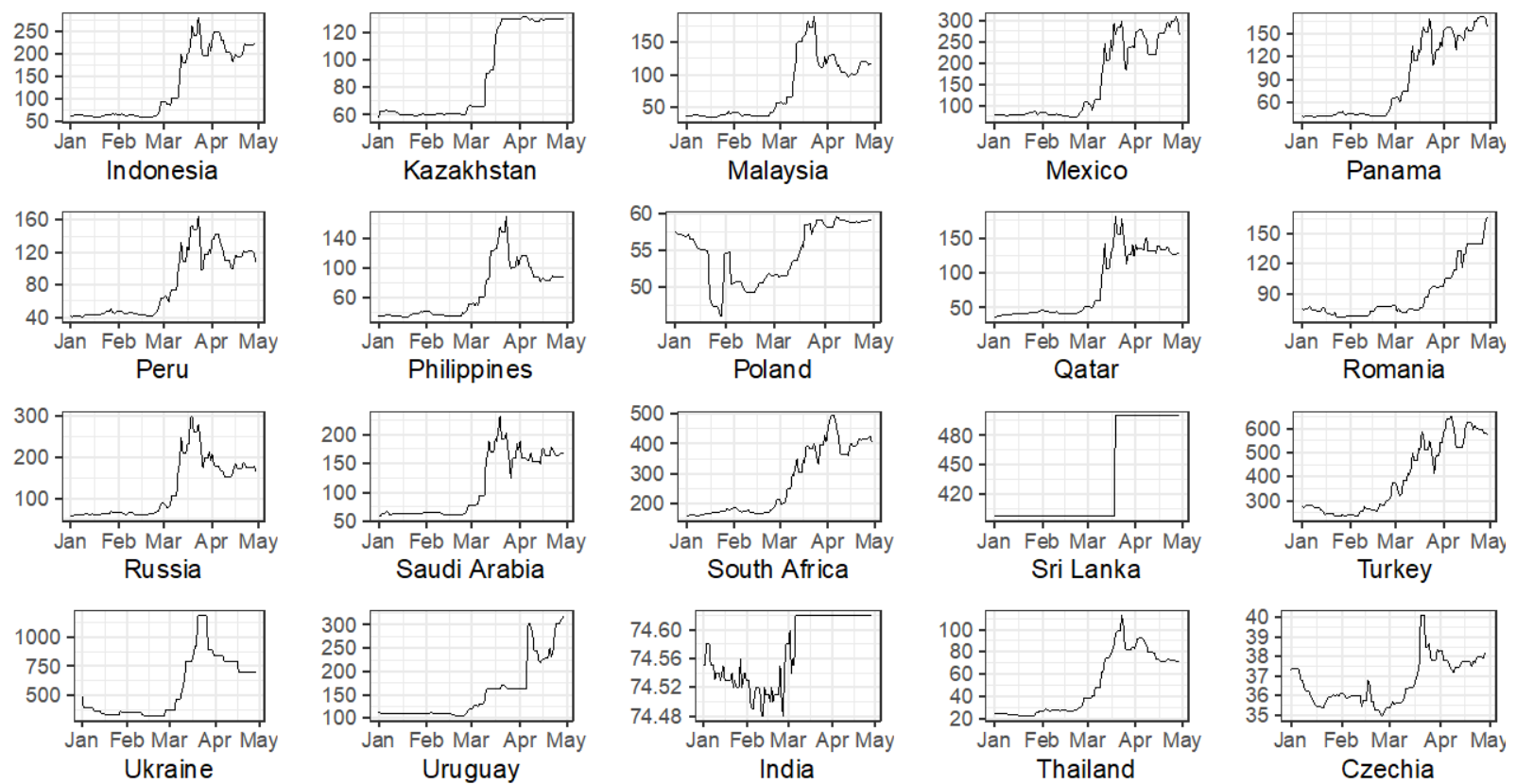

Figure 7: Development of sovereign 5-year CDS spreads of emerging market economies between January 2020 and April 2020. Data source: Eikon Refinitiv. 

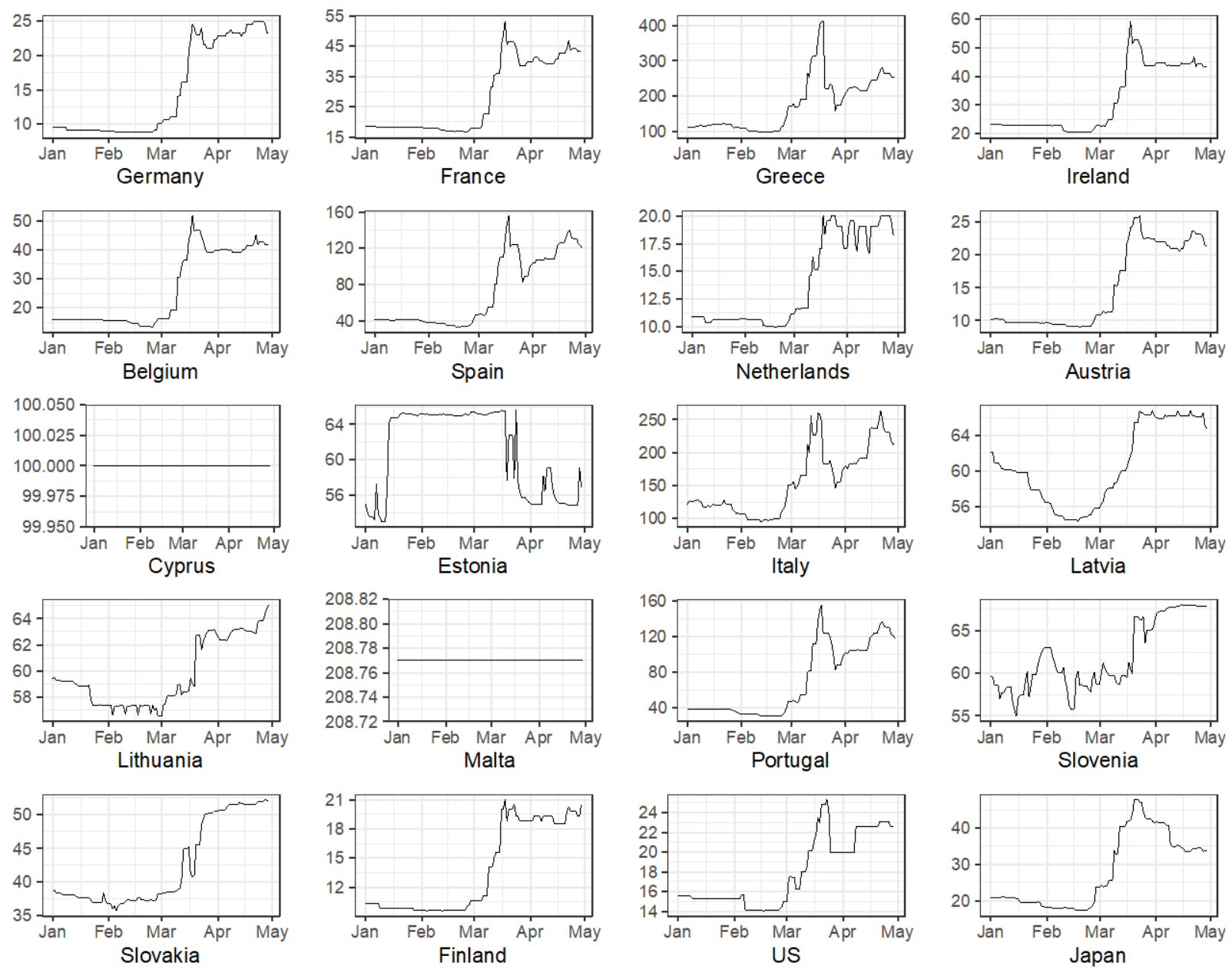

Figure 8: Development of sovereign 5-year CDS spreads of advanced economies between January 2020 and April 2020.

Data source: Eikon Refinitiv.

\begin{tabular}{|l|l|l|l|l|}
\hline Argentina & Bahrain & Brazil & Chile & China \\
\hline Colombia & Czechia & Dominican Republic & Egypt & Ghana \\
\hline Hungary & India & Indonesia & Kazakhstan & Malaysia \\
\hline Mexico & Panama & Peru & Philippines & Poland \\
\hline Qatar & Romania & Russia & Saudi Arabia & South Africa \\
\hline Sri Lanka & Thailand & Turkey & Ukraine & Uruguay \\
\hline
\end{tabular}

Table 1: List of the thirty emerging markets in our large sample. 


\begin{tabular}{|l|l|l|}
\hline Eurozone (33.3\%), 2019 & Japan (12.8\%), 2019 GDP & US (53.9\%), 2019 GDP in \\
GDP in Million USD: & in million USD: 5,081,770 & million USD: 21,427,700 \\
13,264,737 & & \\
\hline Germany, France Greece, & & \\
Ireland, Belgium, Spain, & & \\
Netherlands, Austria, & & \\
Cyprus, Estonia, Italy, & & \\
Latvia, Lithuania, Malta, & & \\
Portugal, Slovenia, & & \\
Slovakia, Finland; & & \\
\hline
\end{tabular}

Table 2: Weights of countries in the global factor are in brackets. The weights are constructed by dividing a country's 2019 GDP by all 20 countries' combined 2019 GDP. Luxemburg is not included in the Eurozone as CDS data was unavailable.

\begin{tabular}{|lllllll|}
\hline Africa & $\begin{array}{l}\text { Central } \\
\text { Asia }\end{array}$ & East Asia & Europe & LATAM & $\begin{array}{l}\text { Middle } \\
\text { East }\end{array}$ & $\begin{array}{l}\text { South } \\
\text { Asia }\end{array}$ \\
Egypt & Kazakhstan & China & Czechia & Argentina & Bahrain & Sri Lanka \\
Ghana & Russia & Indonesia & Hungary & Brazil & Qatar & India \\
South & & Malaysia & Poland & Chile & Saudi & \\
Africa & & Prabia & \\
& & Philippines & Romania & Colombia & & \\
& & Thailand & Turkey & $\begin{array}{l}\text { Dominican } \\
\text { Republic }\end{array}$ & \\
& & Ukraine & $\begin{array}{l}\text { Mexico } \\
\end{array}$ \\
& & & Panama & \\
& & & Peru & \\
& & & Uruguay & \\
\hline
\end{tabular}

Table 3: Classification of large sample into geographic groups. These groups are used to calculate the regional factors in the first-stage regression. Example for China: Indonesia's weight is [Indonesia GDP / (GDP of Indonesia, Malaysia, Philippines, Thailand]. 
EM Average CDS Spreads, Out-of-Sample Period

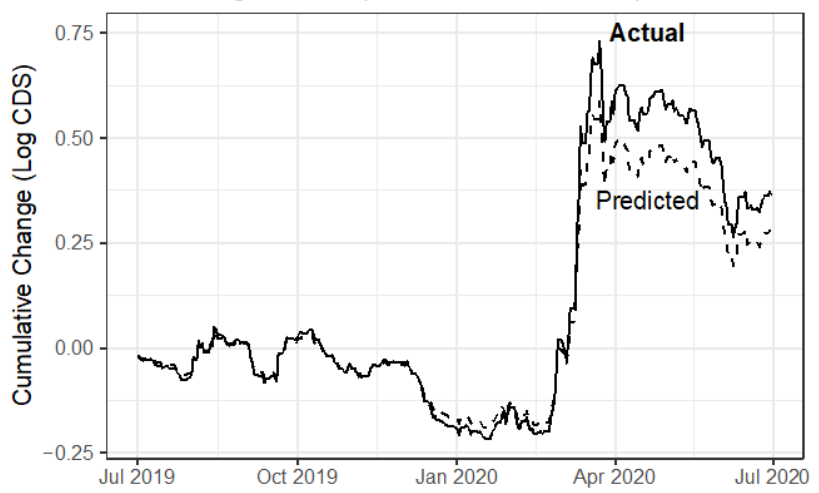

High Vs. Low COVID Mortalities: Actual

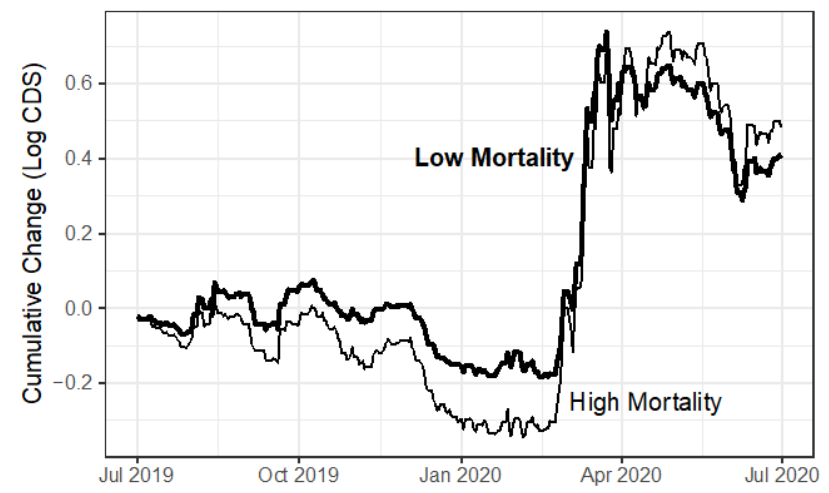

EM CDS Spreads Dispersion

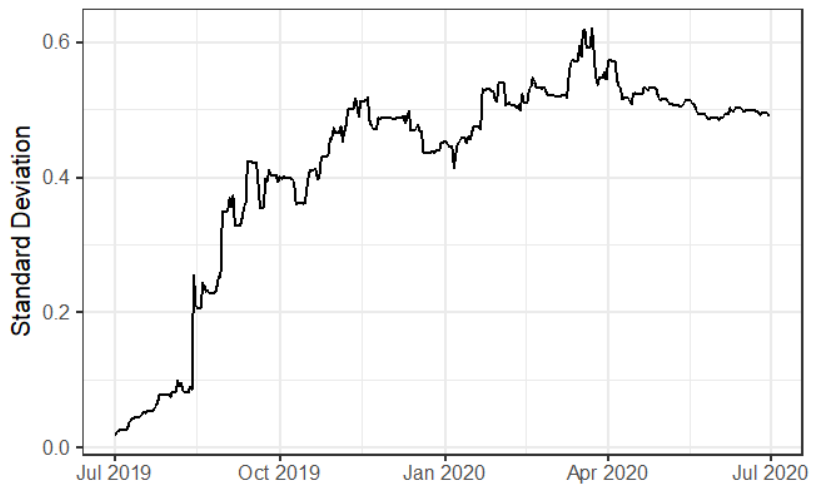

High Vs. Low COVID Mortalities: Actual-Fitted

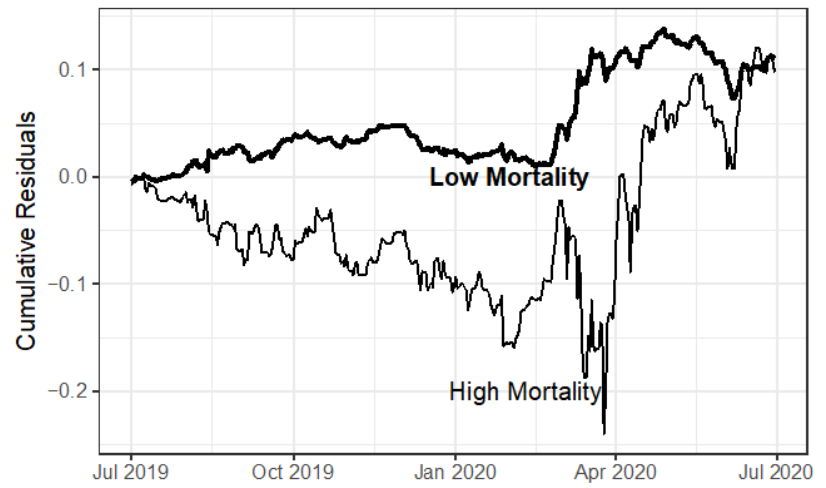

Figure 9: Emerging market spread development, July 2019- June 2020 (reduced sample).
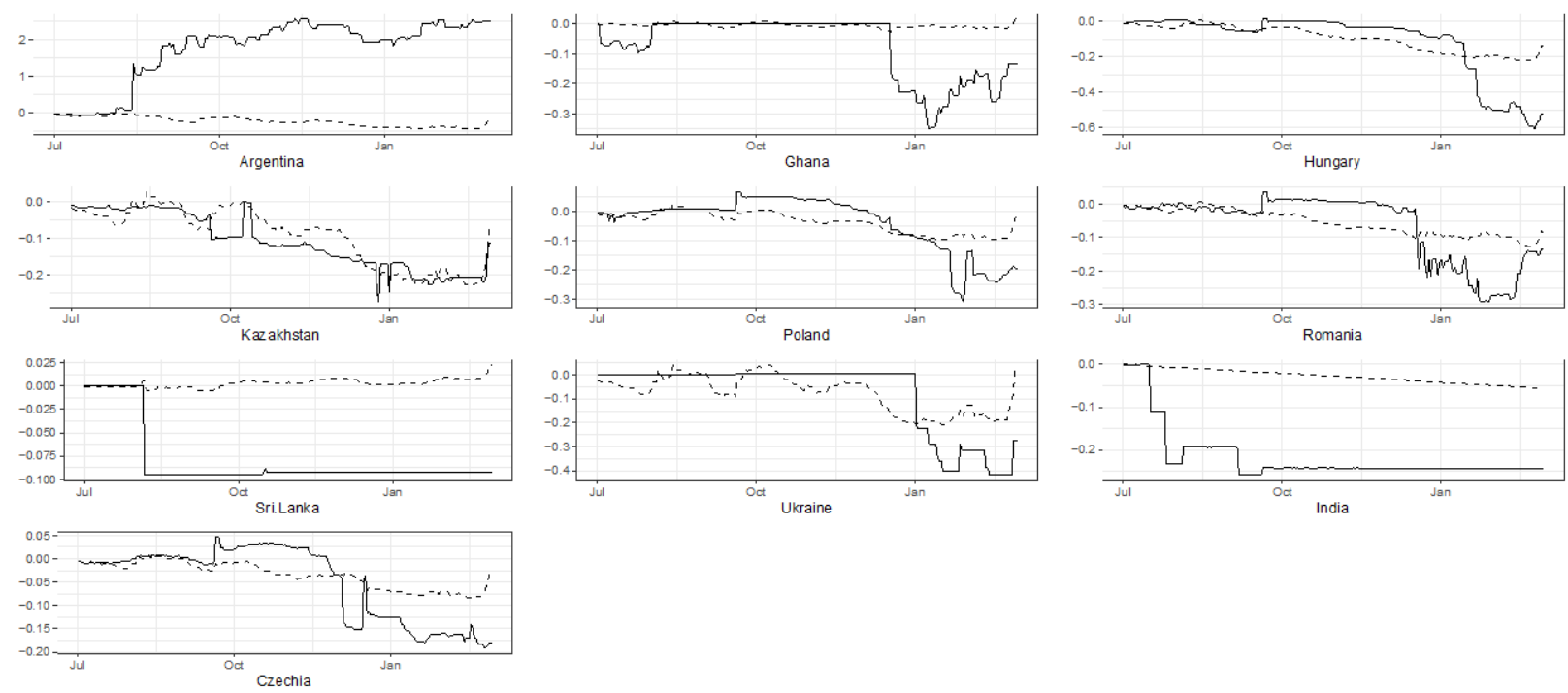

Figure 10: Actual (solid) vs fitted values (dashed) before COVID (July 2019 to January 2020). These are the ten countries for which the correlation coefficient between actual vs fitted values are below 0.25 . That is, the model does not do a good job at predicting the actual values out-of-sample. Therefore, these countries are removed from the full sample and won't be used for the second-stage regressions. 


\begin{tabular}{|c|c|c|c|c|c|c|}
\hline $\begin{array}{l}\text { Dependent Variable: } \\
\qquad C D S_{i, t}\end{array}$ & $\Delta C D S_{i, t-1}$ & $\Delta G C D S_{i^{\prime}, t}$ & $\Delta R C D S_{i^{\prime}, t}$ & R-squared & $\begin{array}{c}\rho_{\triangle C D S_{i, t}, \Delta \widehat{C D S}_{i, t}} \\
\text { Out-of-sample }\end{array}$ & Remains in sample \\
\hline Kazakhstan & $0.058^{* *}$ & $1.605^{* *}$ & $0.67^{* * *}$ & 0.208 & 0.02729761 & No \\
\hline Sri Lanka & $0.101^{* * *}$ & -0.07 & $0.066^{* *}$ & 0.016 & 0.049861621 & No \\
\hline Argentina & -0.034 & $-5.067 * * *$ & $1.355^{* * *}$ & 0.078 & 0.07514264 & No \\
\hline Ghana & $-0.079 * * *$ & -0.094 & $0.179^{* * *}$ & 0.013 & 0.10977094 & No \\
\hline India & 0 & 0.006 & 0.007 & 0 & 0.139835118 & No \\
\hline Hungary & 0.025 & $2.615^{* * *}$ & $0.353^{* * *}$ & 0.16 & 0.141609801 & No \\
\hline Romania & $-0.151 * * *$ & $2.695^{* * *}$ & $0.164^{* * *}$ & 0.098 & 0.153316468 & No \\
\hline Czechia & $-0.07^{* * *}$ & $1.827^{* * *}$ & $0.207^{* * *}$ & 0.104 & 0.154049802 & No \\
\hline Ukraine & -0.002 & -1.709 & $1.033^{* * *}$ & 0.024 & 0.230350506 & No \\
\hline Poland & -0.023 & $2.582^{* * *}$ & $0.298^{* * *}$ & 0.091 & 0.232731083 & No \\
\hline Uruguay & $-0.171 * * *$ & -0.786 & $0.673^{* * *}$ & 0.061 & 0.26073851 & Yes \\
\hline Bahrain & $-0.157^{* * *}$ & 0.996 & $0.26 * * *$ & 0.044 & 0.284288818 & Yes \\
\hline Egypt & -0.007 & 0.437 & $0.139^{* * *}$ & 0.011 & 0.426839517 & Yes \\
\hline Turkey & 0.007 & -0.115 & $1.204^{* * *}$ & 0.305 & 0.582111591 & Yes \\
\hline Saudi Arabia & 0.021 & $2.278^{* * *}$ & $0.652^{* * *}$ & 0.117 & 0.599696373 & Yes \\
\hline Thailand & -0.013 & $2.899 * * *$ & $0.78^{* * *}$ & 0.271 & 0.613012122 & Yes \\
\hline Dominican Republic & $-0.126^{* * *}$ & 0.02 & $0.252^{* * *}$ & 0.043 & 0.63081716 & Yes \\
\hline Qatar & $0.096^{* * *}$ & 0.738 & $0.537^{* * *}$ & 0.129 & 0.663137587 & Yes \\
\hline China & -0.004 & $4.128^{* * *}$ & $1.094^{* * *}$ & 0.335 & 0.673884945 & Yes \\
\hline Russia & $-0.039^{*}$ & -0.33 & $1.338^{* * *}$ & 0.262 & 0.682488479 & Yes \\
\hline Philippines & -0.002 & $3.222^{* * *}$ & $1.008^{* * *}$ & 0.325 & 0.694952732 & Yes \\
\hline Malaysia & 0.001 & $3.999 * * *$ & $1.05^{* * *}$ & 0.303 & 0.704366535 & Yes \\
\hline South Africa & $-0.066^{* * *}$ & 0.233 & $1.352^{* * *}$ & 0.441 & 0.726141132 & Yes \\
\hline Chile & $-0.091^{* * *}$ & -0.456 & $1.729^{* * *}$ & 0.486 & 0.732381358 & Yes \\
\hline Indonesia & 0.01 & $3.041^{* * *}$ & $1.065^{* * *}$ & 0.344 & 0.741153311 & Yes \\
\hline Mexico & $-0.12^{* * *}$ & -0.69 & $1.701^{* * *}$ & 0.46 & 0.789901855 & Yes \\
\hline Brazil & $-0.101^{* * *}$ & $-2.219 * * *$ & $1.483^{* * *}$ & 0.37 & 0.800234627 & Yes \\
\hline Panama & $-0.1^{* * *}$ & 0.597 & $1.534^{* * *}$ & 0.516 & 0.812568178 & Yes \\
\hline Peru & $-0.085^{* * *}$ & -0.283 & $1.635^{* * *}$ & 0.507 & 0.826697317 & Yes \\
\hline Colombia & $-0.081 * * *$ & -0.413 & $1.759^{* * *}$ & 0.543 & 0.838764082 & Yes \\
\hline
\end{tabular}

Note: Country-specific time-series regression estimates from Equation (1).

$*,{ }^{* *},{ }^{* * *}$ correspond to $5 \%, 1 \%$ and $0.1 \%$ significance, respectively. Number of daily observations per country, T, equal to 2,005 . Out-of-sample statistic shows the correlation coefficient between actual CDS spread changes and model-predicted changes for the period outside the estimation sample but before the global outbreak of COVID-19 (July 2019 to February 2020).

Table 4: First-stage regression results of model (1) over the period January 2014 to June 2019. Column 6 provides country-specific out-of-sample correlation coefficients between the actual CDS changes and model-implied CDS changes.

\begin{tabular}{|l|l|}
\hline Countries dropped from full sample & Countries in reduced sample \\
\hline Argentina, Ghana, Hungary, Kazakhstan, & Bahrain, Brazil, Chile, China, Colombia, \\
Poland, Romania, Sri Lanka, Ukraine, & Dominican Republic, Egypt, Indonesia, \\
India, Czechia & Malaysia, Mexico, Panama, Peru, \\
& Philippines, Qatar, Russia, Saudi Arabia, \\
& South Africa, Turkey, Uruguay, Thailand \\
\hline
\end{tabular}

Table 5: List of 20 emerging markets that constitute our reduced sample. The 20 countries were obtained after deleting 10 countries from the full sample based on low correlation coefficients between actual vs fitted values over the pre COVID-19 out-of-sample period July 2019 to February 2020. 

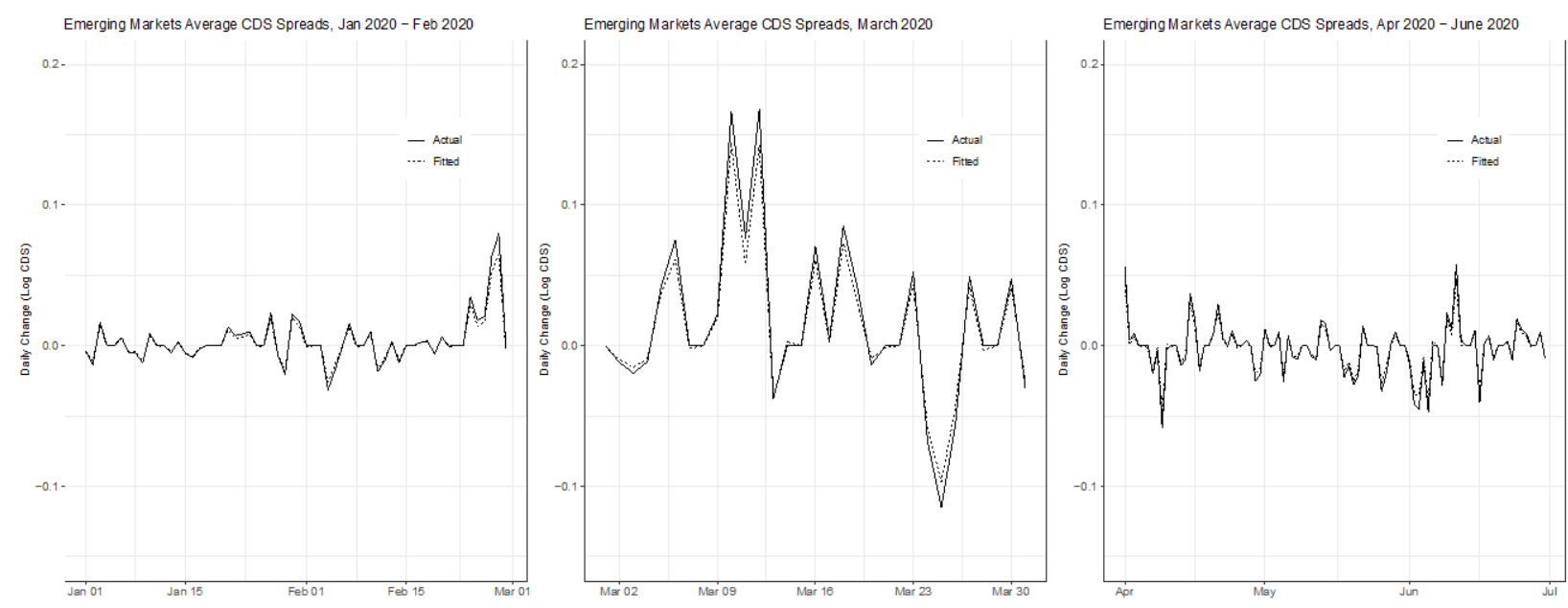

Figure 11: Emerging market average COVID-19 residual (20 country sample). 


\begin{tabular}{|c|c|c|c|}
\hline & \multicolumn{3}{|c|}{ Dependent variable: } \\
\hline & \multicolumn{3}{|c|}{ CDS spread COVID Residual } \\
\hline & $(1)$ & $(2)$ & $(3)$ \\
\hline New Mortality Rate & $\begin{array}{c}0.0285 \\
(0.0391)\end{array}$ & $\begin{array}{c}0.0287 \\
(0.0393)\end{array}$ & $\begin{array}{c}0.1388 \\
(0.1704)\end{array}$ \\
\hline New Mortality Rate Growth & $\begin{array}{c}0.0027 \\
(0.0051)\end{array}$ & $\begin{array}{c}0.0025 \\
(0.0051)\end{array}$ & $\begin{array}{c}0.0020 \\
(0.0055)\end{array}$ \\
\hline Cumulative Mortality Rate & $\begin{array}{l}-0.0071 \\
(0.0092)\end{array}$ & $\begin{array}{l}-0.0073 \\
(0.0091)\end{array}$ & $\begin{array}{l}-0.0307 \\
(0.0394)\end{array}$ \\
\hline Cumulative Mortality Rate Growth & $\begin{array}{l}-0.0278 \\
(0.0202)\end{array}$ & $\begin{array}{l}-0.0275 \\
(0.0208)\end{array}$ & $\begin{array}{c}-0.0407^{*} \\
(0.0245)\end{array}$ \\
\hline SI Growth & & $\begin{array}{l}-0.0092 \\
(0.0194)\end{array}$ & $\begin{array}{l}-0.0063 \\
(0.0224)\end{array}$ \\
\hline ECB Policy Dummy & & & $\begin{array}{c}-0.0882^{* *} \\
(0.0388)\end{array}$ \\
\hline Fed Policy Dummy & & & $\begin{array}{l}-0.0183 \\
(0.0261)\end{array}$ \\
\hline Ext. Debt/GDP & & & $\begin{array}{l}-0.0018 \\
(0.0018)\end{array}$ \\
\hline Ext. Debt/GDP x Fiscal Policy Dummy & & & $\begin{array}{c}0.0006 \\
(0.0006)\end{array}$ \\
\hline Debt owed to China/GDP & & & $\begin{array}{c}0.0077 \\
(0.0403)\end{array}$ \\
\hline Debt owed to China/GDP x Fiscal Policy Dummy & & & $\begin{array}{l}-0.0103 \\
(0.0117)\end{array}$ \\
\hline Oil income effect & & & $\begin{array}{l}-0.0175 \\
(0.0302)\end{array}$ \\
\hline International Reserves/GDP & & & $\begin{array}{l}-0.1521 \\
(0.2914)\end{array}$ \\
\hline Sovereign Wealth Fund volume/GDP & & & $\begin{array}{c}0.5109 \\
(1.1034)\end{array}$ \\
\hline Fixed effects? & $\mathrm{Y}$ & $\mathrm{Y}$ & $\mathrm{Y}$ \\
\hline Observations & 173 & 171 & 153 \\
\hline $\mathrm{R}^{2}$ & 0.0124 & 0.0137 & 0.0647 \\
\hline F Statistic & 0.3781 & 0.3298 & 0.4644 \\
\hline
\end{tabular}

$\begin{array}{ll}\text { Note: } & *, * * * * * \text { correspond to } 10 \%, 5 \% \text { and } 1 \% \text { significance, respectively. } \\ & \text { HAC robust standard errors, clustered by country. Time and Country FEs }\end{array}$

Table 6: Analysis of daily peak COVID-19 residuals (March 2020, 20 country sample). 


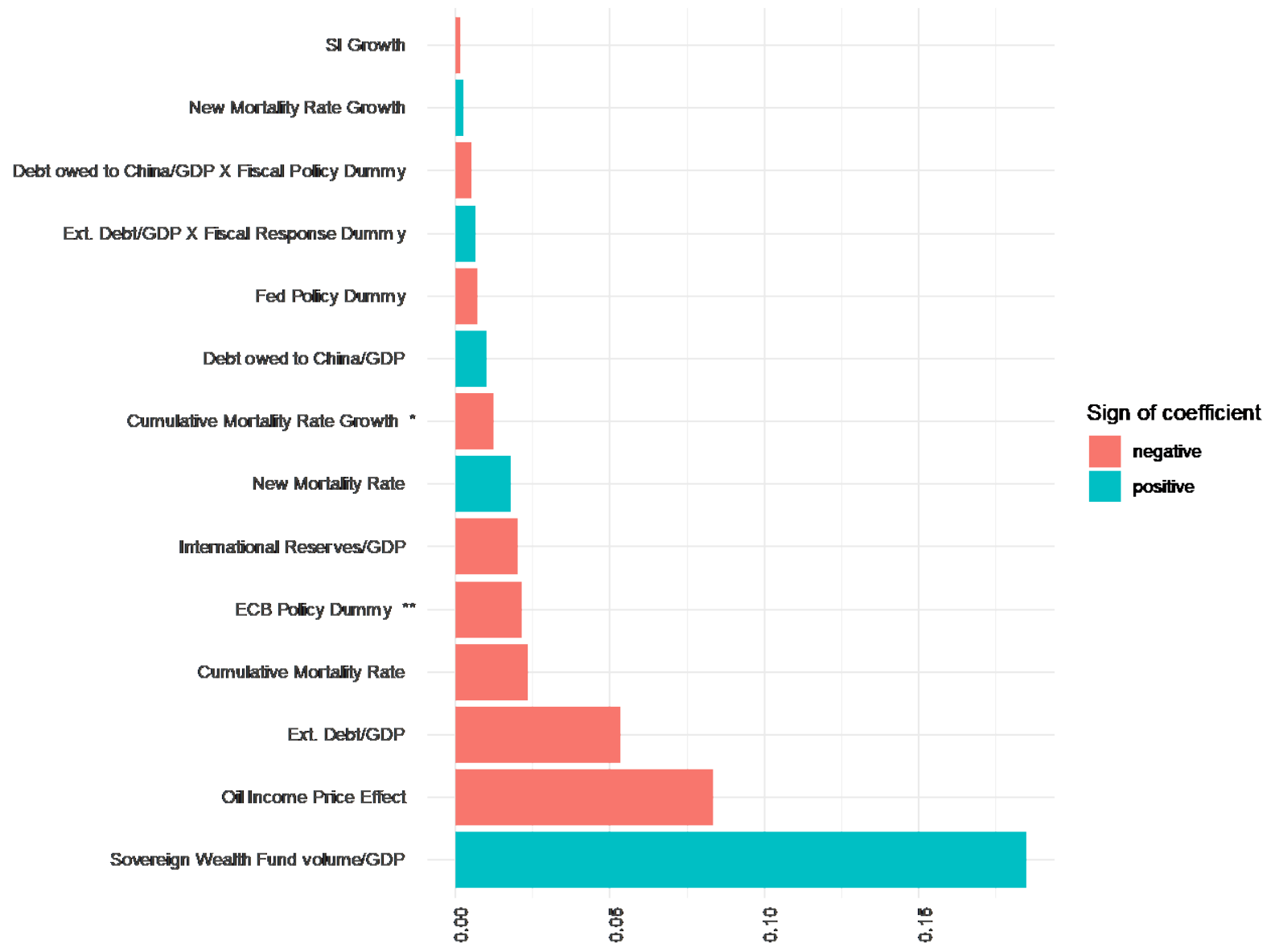

Figure 12: The $x$-axis shows the product of the coefficient estimate and the standard deviation of the variable as absolute values. The coefficients are from Table 6, Analysis of daily peak COVID-19 residuals (March 2020, 20 country sample) model (3). Sigificance levels are attached next to variable names. 


\begin{tabular}{|c|c|c|c|}
\hline & \multicolumn{3}{|c|}{ Dependent variable: } \\
\hline & \multicolumn{3}{|c|}{ Daily CDS Spread Change } \\
\hline & $(1)$ & $(2)$ & $(3)$ \\
\hline Fitted Daily CDS Spread Change & $\begin{array}{c}0.5684^{* *} \\
(0.2698)\end{array}$ & $\begin{array}{c}0.6485^{* *} \\
(0.2620)\end{array}$ & $\begin{array}{c}0.6049^{*} \\
(0.3461)\end{array}$ \\
\hline New Mortality Rate & & $\begin{array}{c}0.0298 \\
(0.0419)\end{array}$ & $\begin{array}{c}0.1499 \\
(0.1623)\end{array}$ \\
\hline New Mortality Rate Growth & & $\begin{array}{c}0.0020 \\
(0.0052)\end{array}$ & $\begin{array}{c}0.0010 \\
(0.0057)\end{array}$ \\
\hline Cumulative Mortality Rate & & $\begin{array}{l}-0.0069 \\
(0.0098)\end{array}$ & $\begin{array}{l}-0.0310 \\
(0.0367)\end{array}$ \\
\hline Cumulative Mortality Rate Growth & & $\begin{array}{l}-0.0267 \\
(0.0196)\end{array}$ & $\begin{array}{r}-0.0393^{*} \\
(0.0234)\end{array}$ \\
\hline SI Growth & & & $\begin{array}{l}-0.0029 \\
(0.0249)\end{array}$ \\
\hline ECB Policy Dummy & & & $\begin{array}{c}-0.0884^{* *} \\
(0.0359)\end{array}$ \\
\hline Fed Policy Dummy & & & $\begin{array}{l}-0.0211 \\
(0.0287)\end{array}$ \\
\hline Ext. Debt/GDP & & & $\begin{array}{l}-0.0019 \\
(0.0016)\end{array}$ \\
\hline Ext. Debt/GDP x Fiscal Policy Dummy & & & $\begin{array}{c}0.0004 \\
(0.0006)\end{array}$ \\
\hline Debt owed to China/GDP & & & $\begin{array}{c}0.0076 \\
(0.0391)\end{array}$ \\
\hline Debt owed to China/GDP x Fiscal Policy Dummy & & & $\begin{array}{l}-0.0086 \\
(0.0120)\end{array}$ \\
\hline Oil income effect & & & $\begin{array}{l}-0.0182 \\
(0.0292)\end{array}$ \\
\hline International Reserves/GDP & & & $\begin{array}{c}-0.1813 \\
(0.2874)\end{array}$ \\
\hline Sovereign Wealth Fund volume/GDP & & & $\begin{array}{c}0.5380 \\
(1.0528)\end{array}$ \\
\hline Fixed effects? & $\mathrm{Y}$ & $\mathrm{Y}$ & $\mathrm{Y}$ \\
\hline Observations & 620 & 173 & 153 \\
\hline $\mathrm{R}^{2}$ & 0.0399 & 0.0687 & 0.1054 \\
\hline F Statistic & $23.6398^{* * *}$ & 1.7567 & 0.7303 \\
\hline
\end{tabular}

Table 7: Analysis of daily peak COVID-19 CDS spread changes (March 2020, 20 country sample). 


\begin{tabular}{|c|c|c|c|c|c|}
\hline & \multicolumn{5}{|c|}{ Dependent variable: } \\
\hline & \multicolumn{5}{|c|}{$\triangle C D S$} \\
\hline & $(1)$ & $(2)$ & $(3)$ & $(4)$ & $(5)$ \\
\hline$\triangle C D S$, lagged & $\begin{array}{c}-0.0114^{* * *} \\
(0.0034)\end{array}$ & $\begin{array}{c}-0.0354^{* * *} \\
(0.0034)\end{array}$ & $\begin{array}{c}-0.0116^{* * *} \\
(0.0035)\end{array}$ & $\begin{array}{c}-0.0144^{* * *} \\
(0.0042)\end{array}$ & $\begin{array}{c}-0.0100^{* *} \\
(0.0040)\end{array}$ \\
\hline$\triangle G C D S$, weighted by core countries' GDP & $\begin{array}{l}2.3390^{* * *} \\
(0.1357)\end{array}$ & $\begin{array}{l}1.3723^{* * *} \\
(0.1392)\end{array}$ & $\begin{array}{l}2.3277^{* * *} \\
(0.1412)\end{array}$ & $\begin{array}{l}2.5620^{* * *} \\
(0.1799)\end{array}$ & $\begin{array}{l}2.4820^{\text {**** }} \\
(0.1779)\end{array}$ \\
\hline$\triangle R C D S$, weighted by regional peers' GDP & $\begin{array}{l}0.5635^{* * *} \\
(0.0045)\end{array}$ & & $\begin{array}{l}0.5776^{* * *} \\
(0.0048)\end{array}$ & $\begin{array}{l}0.5628^{* * *} \\
(0.0062)\end{array}$ & $\begin{array}{l}0.6052^{\text {*** }} \\
(0.0059)\end{array}$ \\
\hline$\triangle R C D S$, weighted by 29 peers' trade shares & & $\begin{array}{l}0.7356^{* * *} \\
(0.0061)\end{array}$ & & & \\
\hline Cumulative Mortality Rate Growth & & & $\begin{array}{l}0.0084^{* *} \\
(0.0034)\end{array}$ & $\begin{array}{l}0.0097^{* *} \\
(0.0042)\end{array}$ & $\begin{array}{l}0.0090^{* *} \\
(0.0043)\end{array}$ \\
\hline SI Growth & & & $\begin{array}{r}0.0046^{*} \\
(0.0026)\end{array}$ & $\begin{array}{l}0.0095^{* * *} \\
(0.0033)\end{array}$ & $\begin{array}{c}0.0050^{*} \\
(0.0030)\end{array}$ \\
\hline Fiscal Response Dummy X stimulus as \% of GDP & & & $\begin{array}{c}0.0228^{* *} \\
(0.0109)\end{array}$ & $\begin{array}{c}0.0288^{* *} \\
(0.0126)\end{array}$ & $\begin{array}{r}0.0226^{*} \\
(0.0127)\end{array}$ \\
\hline ECB Policy Dummy & & & $\begin{array}{l}0.0079^{* * *} \\
(0.0015)\end{array}$ & $\begin{array}{l}0.0068^{* * *} \\
(0.0019)\end{array}$ & $\begin{array}{l}0.0121^{* * *} \\
(0.0019)\end{array}$ \\
\hline Fed Policy Dummy & & & $\begin{array}{c}-0.0001 \\
(0.0008)\end{array}$ & $\begin{array}{c}-0.0005 \\
(0.0010)\end{array}$ & $\begin{array}{c}-0.0004 \\
(0.0010)\end{array}$ \\
\hline Oil Income Price Effect & & & $\begin{array}{c}-0.1527^{* * *} \\
(0.0492)\end{array}$ & $\begin{array}{r}-0.0967 \\
(0.0720)\end{array}$ & $\begin{array}{c}-0.0259 \\
(0.0723)\end{array}$ \\
\hline External debt as \% of GDP & & & $\begin{array}{c}0.00001 \\
(0.00001)\end{array}$ & & \\
\hline Foreign currency debt as $\%$ of GDP & & & & $\begin{array}{c}0.000000 \\
(0.000000)\end{array}$ & \\
\hline Debt to China as \% of GDP & & & & & $\begin{array}{c}-0.0004 \\
(0.0002)\end{array}$ \\
\hline International reserves as $\%$ of GDP & & & $\begin{array}{c}0.0007 \\
(0.0021)\end{array}$ & $\begin{array}{c}-0.0018 \\
(0.0033)\end{array}$ & $\begin{array}{c}0.0009 \\
(0.0050)\end{array}$ \\
\hline Fixed effects? & $\mathrm{Y}$ & Y & Y & Y & $\mathrm{Y}$ \\
\hline Observations & 70,742 & 70,742 & 66,040 & 47,194 & 49,529 \\
\hline $\mathrm{R}^{2}$ & 0.2026 & 0.1889 & 0.2084 & 0.1703 & 0.1995 \\
\hline F Statistic & $5,987.3740^{* * *}$ & $5,488.3030^{* * *}$ & $1,579.6010^{* * *}$ & $880.0748^{* * *}$ & $1,121 \cdot 1270^{* * *}$ \\
\hline
\end{tabular}

$* * * * * *$ correspond to $10 \%, 5 \%$ and $1 \%$ significance, respectively.

HAC robust standard errors, clustered by country. Country FEs.

Table 8: Analysis of daily CDS spread changes (January 2014 to June 2020, 30 country sample). 


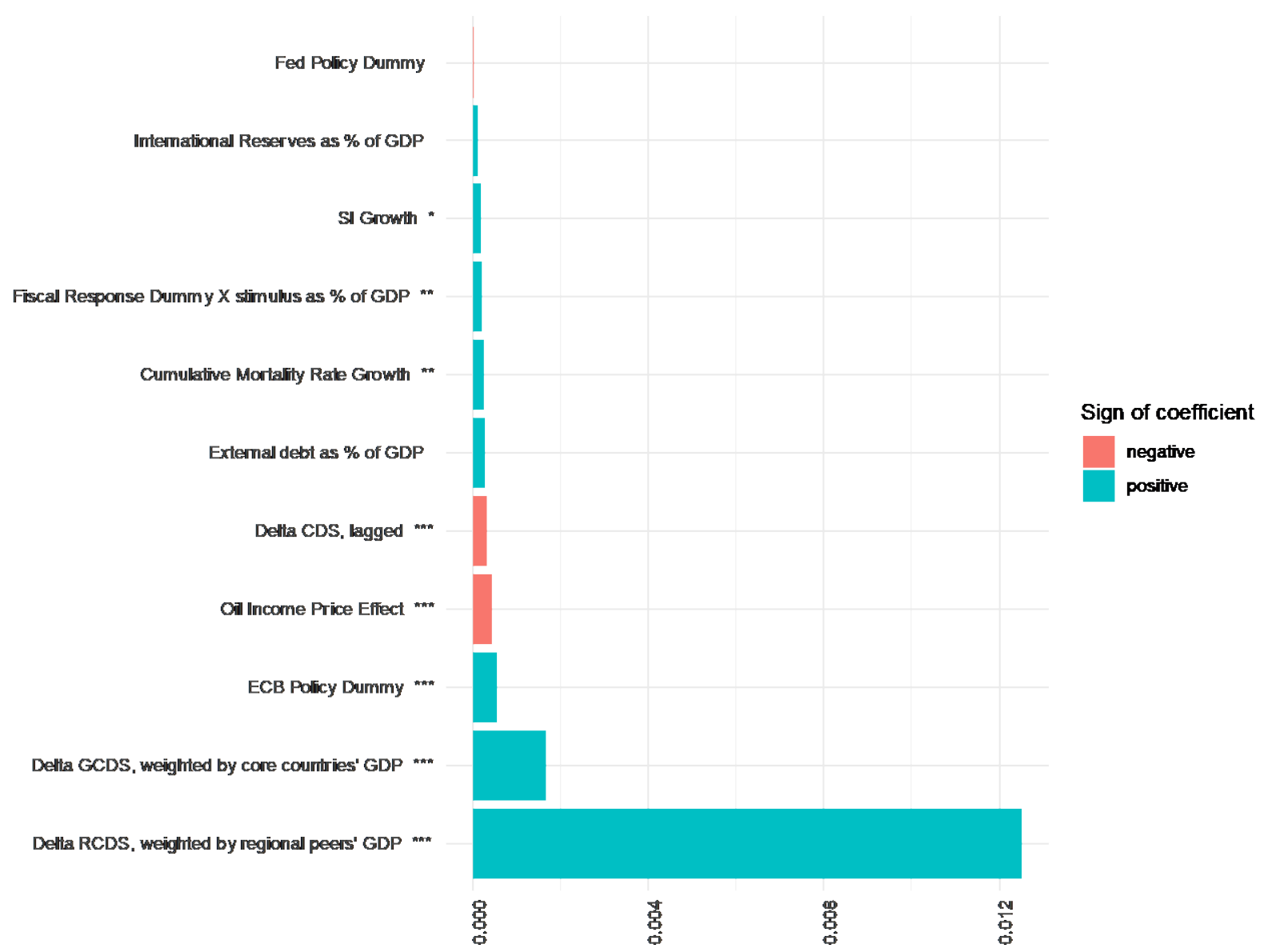

Figure 13: The $x$-axis shows the product of the coefficient estimate and the standard deviation of the variable as absolute values of daily CDS spread changes, January 2014 - June 2020, 30 country sample. The coefficients are from Table 8 model (3). Sigificance levels are attached next to variable names. 


\section{Bibliography}

Ahmed, S., Coulibaly, B., \& Zlate, A. (2017). International financial spillovers to emerging market economies: How important are economic fundamentals? Journal of International Money and Finance, 76, 133-152.

Alberola-lla, E., Arslan, Y., Cheng, G., \& Moessner, R. (2020). The fiscal response to the Covid-19 crisis in advanced and emerging market economies (No. 23). Bank for International Settlements.

Augustin, P., Subrahmanyam, M. G., Tang, D. Y., \& Wang, S. Q. (2014). Credit default swaps-A survey. Foundations and Trends in Finance, 9(1-2), 1-196.

Bahaj, S., \& Reis, R. (2020). Central bank swap lines during the Covid-19 pandemic. Covid Economics, 2, 1-12.

Cepni, O., Kucuksarac, D., \& Yilmaz, M. H. (2017). The sensitivity of credit default swap premium to global risk factor: Evidence from emerging markets. Economics Letters, 159, 74-77.

Fender, I., Hayo, B., \& Neuenkirch, M. (2012). Daily pricing of emerging market sovereign CDS before and during the global financial crisis. Journal of Banking \& Finance, 36(10), 2786-2794.

Horn, S., Reinhart, C. M., \& Trebesch, C. (2019). China's overseas lending (No. w26050). National Bureau of Economic Research.

Jinjarak, Y., Ahmed, R., Nair-Desai, S., Xin, W., \& Aizenman, J. (2020). Accounting for global COVID-19 diffusion patterns, January-April 2020. Economics of disasters and climate change, 4(3), 515-559.

Kocsis, Z., \& Monostori, Z. (2016). The role of country-specific fundamentals in sovereign CDS spreads: Eastern European experiences. Emerging Markets Review, 27, 140-168.

Nouvellet, P., Bhatia, S., Cori, A., Ainslie, K. E., Baguelin, M., Bhatt, S., ... \& Donnelly, C. A. (2021). Reduction in mobility and COVID-19 transmission. Nature communications, 12(1), 1-9.

Remolona, E. M., Scatigna, M., \& Wu, E. (2008). The dynamic pricing of sovereign risk in emerging markets: Fundamentals and risk aversion. The Journal of Fixed Income, 17(4), 57-71.

Rey, H. (2015). Dilemma not trilemma: the global financial cycle and monetary policy independence (No. w21162). National Bureau of Economic Research. 
Young, A. (2005). The gift of the dying: The tragedy of AIDS and the welfare of future African generations. The Quarterly Journal of Economics, 120(2), 423-466. 